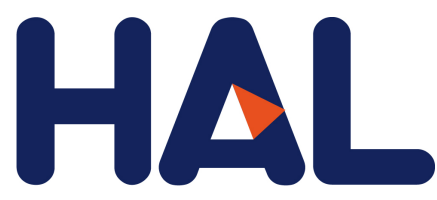

archives-ouvertes

\title{
Congruent population genetic structures and divergence histories in anther-smut fungi and their host plants Silene italica and the S. nutans species complex
}

Fanny Hartmann, Alodie Snirc, Amandine Cornille, Cécile Godé, Pascal Touzet, Fabienne van Rossum, Elisabeth Fournier, Stéphanie Prieur, Jacqui Shykoff, Tatiana Giraud

\section{To cite this version:}

Fanny Hartmann, Alodie Snirc, Amandine Cornille, Cécile Godé, Pascal Touzet, et al.. Congruent population genetic structures and divergence histories in anther-smut fungi and their host plants Silene italica and the S. nutans species complex. Molecular Ecology, Wiley, 2020, 10.1101/2020.01.04.894774 . hal-03334873

\section{HAL Id: hal-03334873 \\ https://hal.archives-ouvertes.fr/hal-03334873}

Submitted on 5 Sep 2021

HAL is a multi-disciplinary open access archive for the deposit and dissemination of scientific research documents, whether they are published or not. The documents may come from teaching and research institutions in France or abroad, or from public or private research centers.
L'archive ouverte pluridisciplinaire HAL, est destinée au dépôt et à la diffusion de documents scientifiques de niveau recherche, publiés ou non, émanant des établissements d'enseignement et de recherche français ou étrangers, des laboratoires publics ou privés. 


\section{Congruent population genetic structures and divergence histories in anther- 2 smut fungi and their host plants Silene italica and the $\boldsymbol{S}$. nutans species 3 complex}

\section{Running title:}

6 Co-structure of anther-smuts and their hosts

8 Fanny E. Hartmann ${ }^{1}$, Alodie Snirc ${ }^{1}$, Amandine Cornille ${ }^{2}$, Cécile Godé $^{3}$, Pascal Touzet ${ }^{3}$, Fabienne 9 Van Rossum ${ }^{4,5}$, Elisabeth Fournier ${ }^{6}$, Stéphanie Le Prieur ${ }^{1}$, Jacqui Shykoff ${ }^{1}$, Tatiana Giraud ${ }^{1}$

$111^{1}$ Ecologie Systématique Evolution, Bâtiment 360, Univ. Paris-Sud, AgroParisTech, CNRS,

12 Université Paris-Saclay, 91400 Orsay, France;

132 Génétique Quantitative et Evolution-Le Moulon, INRA; Univ. Paris-Sud, CNRS, 14 AgroParisTech, Université Paris-Saclay, 91198 Gif-sur-Yvette, France;

$15{ }^{3}$ Univ. Lille, CNRS, UMR 8198 - Evo-Eco-Paleo, F-59000 Lille, France;

$16{ }^{4}$ Meise Botanic Garden, B-1860 Meise, Belgium;

$17 \quad{ }^{5}$ Fédération Wallonie-Bruxelles, B-1080 Brussels, Belgium;

$18{ }^{6}$ UMR BGPI, Univ. Montpellier, INRA, CIRAD, Montpellier SupAgro, Montpellier, France;

$20 *$ Author for Correspondence: Fanny E. Hartmann, Ecologie Systematique Evolution, Bâtiment 21 360, Univ. Paris-Sud, AgroParisTech, CNRS, Université Paris-Saclay, 91400 Orsay, France, 22 phone number : 01691572 82, e-mail address: fanny.hartmann@u-psud.fr 


\section{Abstract}

25 The study of population genetic structure congruence between hosts and pathogens gives

26 important insights into their shared phylogeographic and coevolutionary histories. We studied the

27 population genetic structure of castrating anther-smut fungi (Microbotryum genus) and of their

28 host plants, the Silene nutans species complex, and the morphologically and genetically close $S$.

29 italica, which can be found in sympatry. Phylogeographic population genetic structure related to

30 persistence in separate glacial refugia has been recently revealed in the $S$. nutans plant species

31 complex across Western Europe, identifying several distinct lineages. We genotyped 171

32 associated plant-pathogen pairs of anther-smut fungi and their host plant individuals using

33 microsatellite markers and plant chloroplastic SNPs. We found clear differentiation between

34 fungal populations parasitizing $S$. nutans and $S$. italica plants. The population genetic structure of

35 fungal strains parasitizing the $S$. nutans plant species complex mirrored the host plant genetic

36 structure, suggesting that the pathogen was isolated in glacial refugia together with its host and/or

37 that it has specialized on the plant genetic lineages. Using random forest approximate Bayesian

38 computation (ABC-RF), we found that the divergence history of the fungal lineages on S. nutans

39 was congruent with the one previously inferred for the host plant and likely occurred with ancient

40 but no recent gene flow. Genome sequences confirmed the genetic structure and the absence of

41 recent gene flow between fungal genetic lineages. Our analyses of host-pathogen individual pairs

42 contribute to a better understanding of co-evolutionary histories between hosts and pathogens in

43 natural ecosystems, in which such studies are still scarce.

45 Key words: population genetic structure, host-pathogen interaction, cryptic speciation, genetic

46 divergence, approximate Bayesian computation, coevolution 


\section{Introduction}

48 Host-pathogen interactions are pervasive in natural ecosystems, with many important ecological

49 and evolutionary consequences (Poulin, 2005; Thompson, 2005). Pairs of tightly interacting hosts

50 and pathogens may share common evolutionary histories due to co-evolution and/or shared

51 geographic and climatic constraints, or may follow distinct evolutionary trajectories due to

52 differences in reproductive systems, dispersal ranges, population sizes or contingent histories

53 (Tellier, de Vienne, Giraud, Hood, \& Refrégier, 2010; Thompson, 2005). The comparison of

54 genetic divergence histories between host and pathogen populations gives important insights into

55 their shared phylogeographic history and possible local adaptation or host specialization (Croll \&

56 Laine, 2016; Feurtey et al., 2016). Studies of phylogeny congruence of hosts and pathogens can

57 for example allow identifying host shifts or co-speciation events (de Vienne et al., 2013; Hafner

58 \& Page, 1995; Wilson, Falush, \& McVean, 2005). Several cases of host shift or co-speciation

59 events between hosts and pathogens have led to damaging diseases in plants, animals and humans

60 (Fisher, Gow, \& Gurr, 2016; McDonald \& Stukenbrock, 2016; Wolfe, Dunavan, \& Diamond,

61 2007). The study of population genetic structure congruence within species or species complexes

62 can help identifying and understanding patterns of local adaptation (Gandon, Capowiez, Dubois,

63 Michalakis, \& Olivieri, 1996), which play an important role in the dynamics of pathogen and host

64 communities (Gandon \& Michalakis, 2002; Laine, 2005; Laine, 2008). Studies investigating the

65 congruence of population genetic structure and divergence histories between hosts and pathogens

66 are yet surprisingly still scarce despite their importance for understanding the evolutionary

67 mechanisms and histories leading to host specialization and local adaptation (Barrett, Thrall,

68 Burdon, \& Linde, 2008; Croll \& Laine, 2016), but see (Dybdahl \& Lively, 1996; Feurtey et al.,

69 2016; McCoy, Boulinier, \& Tirard, 2005; Michalakis, Sheppard, Noel, \& Olivieri, 1993; Tsai \& 
Manos, 2010).

71 Anther-smut fungi (Microbotryum genus) are generally highly specialized on their host plant

72 species of the Caryophyllaceae family (Hartmann et al., 2019; Kemler, Göker, Oberwinkler, \&

73 Begerow, 2006; Le Gac, Hood, Fournier, \& Giraud, 2007; Refrégier et al., 2008) and patterns of

74 local adaptation have been reported in the system (Feurtey et al., 2016; Kaltz, Gandon,

75 Michalakis, \& Shykoff, 1999). Therefore, they constitute a highly suitable system to study the

76 congruence of population genetic structure and divergence history between hosts and pathogens

77 at different evolutionary scales. Comparisons of phylogenies at the genus level suggested a

78 prevalence of host shifts at large evolutionary scales (Refrégier et al., 2008). The plant Silene

79 latifolia and its anther-smut fungus M. lychnidis-dioicae display strong congruence of population

80 genetic structures and plant local adaptation at regional and continental scales, suggesting the

81 existence of co-evolution in the system (Delmotte, Bucheli, \& Shykoff, 1999; Feurtey et al.,

82 2016; Kaltz et al., 1999). Population genetic structures of both the host and the fungal pathogen

83 likely resulted from past climatic events, showing hallmarks of recolonization from former

84 glacial refugia in Europe (Badouin et al., 2017; Gladieux, Devier, Aguileta, Cruaud, \& Giraud,

85 2013; Gladieux et al., 2011; Taylor \& Keller, 2007; Vercken et al., 2010). The congruence of

86 host and pathogen population genetic structures has not been investigated in other anther-smut

87 fungi-Silene pairs despite their importance as models of pathosystems in natural ecosystems

88 (Bernasconi et al., 2009; Toh \& Perlin, 2016) and the importance of assessing whether

89 congruence in population genetic subdivision is a general pattern (Croll \& Laine, 2016).

90 Furthermore, the evolutionary history of population genetic divergence and of gene flow levels

91 occurring between pathogens infecting closely related hosts with overlapping distribution ranges

92 still remain poorly studied at the genome-wide-scale (but see Badouin et al., 2017). 
93 Silene nutans is an assemblage of strongly differentiated cryptic genetic plant lineages,

94 corresponding to at least seven "evolutionary significant units", which can be grouped into two

95 main phylogeographic (eastern and western) genetic clusters in Europe (Van Rossum et al.,

96 2018). The $S$. nutans genetic lineages display several morphological and ecological differences,

97 as well as nuclear and plastid genetic differentiation (Martin et al., 2016; Van Rossum et al.,

98 2018), and strong postzygotic reproductive isolation has been shown between the eastern and

99 western clusters in Western Europe (Martin et al., 2017). Geographic distribution patterns suggest

100 that $S$. nutans lineages have diverged in allopatry during the Quaternary climate oscillations, and

101 then recolonized northwards, without admixture (Martin et al., 2016; Martin et al., 2017; Van

102 Rossum et al., 2018). The anther-smut fungal species Microbotryum violaceum sensu stricto is

103 specialized on S. nutans (Kemler et al., 2006; Lutz et al., 2005). Microbotryum fungi are

104 pollinator-borne pathogens castrating plants by replacing the pollen by their own spores and

105 aborting ovaries, and they are usually highly specific on their Silene host plant species (Le Gac,

106 Hood, \& Giraud, 2007; Refrégier et al., 2008). The existence of cryptic lineages within S. nutans

107 therefore raises the question of whether cryptic lineages also exist in the fungus and whether their

108 genetic divergence history mirrors that of the host. In Southern Europe, S. nutans can be found in

109 sympatry with $S$ italica, a closely related species, in particular in the Cévennes (Lafuma \&

110 Maurice, 2006). Silene nutans and S. italica can be difficult to distinguish, being very similar

111 morphologically, mainly differing in petal shape, in the length of the gynophore and with rather

112 nodding or erect flowers, respectively (Rameau, Mansion, \& Dumé, 1989, 2008; Tison \& de

113 Foucault, 2014). Their flowering time, pollinator guilds and ecological niches overlap, although

114 they slightly differ in their ecological requirements, with $S$. italica being strictly calcicolous,

115 more xero-thermophilous and heliophilous than S. nutans (Rameau et al., 1989, 2008; Tutin et al.,

116 2001). Microbotryum fungi have been found on the two plant species and appeared differentiated 
117 based on a small sample and a few genetic markers (Bucheli, Gautschi, \& Shykoff, 2000);

118 however, spillover, i.e., non-sustainable cross-species disease transmission, has been shown to

119 occur in Microbotryum fungi (Antonovics, Hood, \& Partain, 2002; Gladieux et al., 2011). The

120 study of the population genetic structure of M. violaceum s. s. on S. nutans therefore requires

121 molecular typing to check plant and fungal species identities.

122 In this study, we analyzed associated plant-pathogen samples of $S$. nutans and S. italica

123 populations from Europe in order to address the following questions: 1) Is there genetic

124 differentiation between anther-smut fungi parasitizing the closely related plant species S. nutans

125 and $S$. italica? Are there hybrids and/or spill-overs in anther-smut fungi? 2) Is the population

126 genetic structure of the anther-smut fungi parasitizing $S$. nutans and $S$. italica congruent with

127 those of their hosts? 3) What is the divergence history of these anther-smut fungi on their hosts?

128 Did genetic divergence occur with gene flow? Does the divergence history of the fungi mirror

129 that of their hosts? In order to address these questions, we used genetic markers (nuclear

130 microsatellite markers and/or chloroplastic SNPs) in both plants and anther-smut fungi to analyse

131 diseased material (171 plant-pathogen pairs) collected across Western Europe and infer

132 population genetic structures. We used approximate Bayesian computation (ABC) to compare

133 genetic divergence scenarios in anther-smut fungi in order to assess whether the genetic

134 divergence history in anther-smut fungi mirrored that inferred previously for their host plants. We

135 also sequenced 53 genomes of Microbotryum fungi and analysed them together with 46 available

136 Microbotryum genomes to assess whether the inferences on population genetic structure and gene

137 flow based on microsatellite markers hold at the genome-wide levels and whether there were 138 spill-overs or gene flow from other sympatric Microbotryum species than those analysed with

139 microsatellite markers. 


\section{Materials and Methods}

\section{Fungal and plant materials}

143 We analyzed 171 anther-smut fungi collected from diseased plant individuals of $S$. nutans and $S$.

144 italica that were sampled in 55 distinct geographic sites across Europe, including the United

145 Kingdom, France, Belgium, Switzerland, Italy, Germany and Norway (Table S1, Fig. 1A).

146 Diseased plant individuals were stored in individual paper envelops kept in plastic bags filled

147 with silica gel, in dark conditions at $8^{\circ} \mathrm{C}$. Small pieces of leaves were used as raw material for

148 DNA extraction of host plant individuals. Diploid spores of Microbotryum anther-smut fungi

149 were collected in buds of infected flowers and grown as yeasts on potato dextrose agar (PDA)

150 medium, and then stored at $-20^{\circ} \mathrm{C}$. Spores did not grow for a few samples older than two years.

151 For DNA extraction of these strains, we used the dried spores directly collected from anthers of

152 diseased flowers. In most cases, spores from anthers of a single flower were used and therefore

153 corresponded to a single Microbotryum genotype (López-Villavicencio et al., 2007). When spore

154 material was limited, we used multiple anthers from several flowers of the same plant. We never

155 observed more than two alleles per strain and found low levels of heterozygosity per strain,

156 indicating that we unlikely genotyped more than one fungal genotype.

158 Genotyping and identification of species and genetic lineages of the Silene plants based on

159 nuclear microsatellite markers and chloroplastic SNPs

160 We extracted plant DNA of at least one diseased plant individual per site using the NucleoSpin ${ }^{\circledR}$

16196 Plant II kit (Macherey-Nagel, Germany). We obtained DNA for 134 out of the 171 diseased 
162 plant individuals. At least one host individual was genotyped per site, except for six sites due to

163 the lack of plant material (Table S1). In addition, we genotyped three plant individuals for which

164 no anther-smut fungus was isolated but strains were isolated at the same sites (Table S1). Using 165 morphological criteria of the host plant species, sample collectors initially identified $153 S$. 166 nutans and 18 S. italica diseased individuals. However, as the morphologies of $S$. nutans and $S$.

167 italica are very similar, misidentification could occur. Therefore, we sequenced four chloroplast 168 fragments (psbA, LF, MATK, GS; Lahiani et al., 2013) to check species identity of the diseased 169 plants collected in southeastern France and in Italy, where both S. nutans and S. italica can be

170 found. We thus reassigned one individual to $S$. nutans and seven individuals to $S$. italica, while 171 one host individual could not be assigned to either $S$. nutans or $S$. italica species (from the pair \# 172 1436). We excluded this host-pathogen individual pair from our analyses. We thus had 145 173 diseased S. nutans plants and 25 diseased S. italica plant (Table S1).

175 To further genotype the plant individuals for studying the population genetic structure, we used a 176 combination of plastid (chloroplast) SNPs and nuclear microsatellite markers as previously 177 described (Godé et al., 2014; Martin et al., 2016; Martin et al., 2017). For plastid markers, using 178 the KASPAR ${ }^{\circledR}$ protocol we genotyped six SNPs, named Cp42, Cp397, Cp540, Cp656, Cp730 179 and $\mathrm{Cp} 804$, and polymorphic for $[\mathrm{T} / \mathrm{G}],[\mathrm{A} / \mathrm{C}],[\mathrm{C} / \mathrm{T}],[\mathrm{G} / \mathrm{T}],[\mathrm{C} / \mathrm{T}]$, and $[\mathrm{T} / \mathrm{G}]$, respectively. 180 Individual haplotypes were defined as combinations of allelic states for all six SNPs. For nuclear 181 markers, we used six multiplexes genotyping 24 microsatellite markers (Table S2). We followed 182 the previously published protocols (Godé et al., 2014; Martin et al., 2016; Martin et al., 2017), 183 except that we used different dye colors, bought from Eurofins Genomics. We used the Multiplex 184 PCR Kit (Qiagen) following manufacturer instructions for PCR reactions, performed separately 185 for each multiplex in $15 \mu \mathrm{L}$ volume containing $3 \mu \mathrm{L}$ of DNA, $3.4 \mu \mathrm{L}$ of $\mathrm{H} 2 \mathrm{O}, 7.1 \mu \mathrm{L}$ of multiplex 
PCR Kit (Buffer 2X, Qiagen, USA), and $1.4 \mu \mathrm{L}$ of the primer mix. The primer mix included 2

$187 \mu \mathrm{M}$ of unlabelled forward and reverse primers and $0.5 \mu \mathrm{M}$ or $0.75 \mu \mathrm{M}$ of the labelled forward

188 primer depending on the dye label. We used the same PCR cycling program as described in

189 (Godé et al., 2014) with some modifications of the final elongation for multiplex 1 (Table S3A-

190 C). We checked successful PCR amplifications on $2 \%(w / v)$ agarose gel electrophoresis. We

191 outsourced genotyping at the Gentyane Genotyping Platform (INRA, Clermont, France) and

192 scored alleles with GENEMAPPER v.4.0 (Applied Biosystems). We excluded three markers

193 (SIL18, SIL26, SIL42) for which we had less than 50\% of the individuals successfully

194 genotyped. Given the material available, we could genotype 136 host plant individuals using both

195 plastid SNPs and nuclear microsatellite markers. All 136 genotyped host individuals had a

196 determined plastid haplotype and a determined genotype for at least $50 \%$ of the 21 remaining

197 nuclear microsatellite markers. The genotypes are deposited on Dryad (accession available upon 198 acceptance).

200 Genotyping and species identification of the Microbotryum fungal strains: microsatellite 201 markers and ITS sequences

202 We extracted fungal DNA using the Chelex protocol (Biorad, USA) following (Giraud, 2004).

203 We extracted DNA from the 170 strains of anther-smut fungi, either from mixes, stored at $-20^{\circ} \mathrm{C}$,

204 of haploid sporidia resulting from clonal growth after meiosis or from diploid teliospores directly

205 collected in anthers of diseased flowers and stored at $10^{\circ} \mathrm{C}$. Diploid genomes were therefore

206 genotyped. DNA was diluted half-fold for PCR amplification. We used the internal transcribed

207 spacer (ITS) to check that the genus of the fungal strains belonged to the Microbotryum genus.

208 To genotype the fungal strains, we used 22 microsatellite markers arranged into multiplex (Table

209 S4 ; (Fortuna et al., 2016; Giraud et al., 2008)). We used the Multiplex PCR Kit (Qiagen) 
210 following manufacturer instructions for PCR reactions which were performed separately for each

211 multiplex as described above. We used the PCR cycling programs as in previous studies (Fortuna

212 et al., 2016; Giraud et al., 2008; Table S3C-D). We checked the success of PCR amplifications on

$2132 \%$ agarose gel electrophoresis. For genotyping, we pooled multiplexes 7 and 8 as a single

214 multiplex. We outsourced genotyping at the Gentyane Genotyping Platform (INRA, Clermont,

215 France) and scored alleles with GENEMAPPER v.4.0 (Applied Biosystems). We could

216 determine the genotypes for all strains for at least $50 \%$ of the 22 markers. We identified 21 fungal

217 strains that were likely siblings of other fungal strains based on null genetic distances and we

218 excluded them from the STRUCTURE software analyses (see below).

\section{Population genetic structure based on microsatellite markers}

221 To analyze and compare host and pathogen population genetic structures, we used a combination

222 of three complementary approaches using microsatellite nuclear markers on both the Silene host

223 plants and anther-smut fungal datasets. First, we used the model-based Bayesian clustering

224 approach implemented in the software STRUCTURE version 2.3.4 (Pritchard, Stephens, \&

225 Donnelly, 2000). The program performs partitions of multilocus genotypes into genetic clusters

226 and assigns individuals to genetic clusters, minimizing the departure from expected frequencies

227 and linkage equilibrium among loci. We tested an admixture model with correlated frequencies

228 and no prior information for $\mathrm{K}=2$ to $\mathrm{K}=10$ clusters. A total of 10 repetitions were run for each

229 K value. We used 50,000 samples as a burn-in period and 100,000 samples per run for the Monte

230 Carlo Markov Chain (MCMC) replicates. Cluster assignment probabilities were computed using

231 the CLUMPP program (Jakobsson \& Rosenberg, 2007) implemented in the R package

232 \{Pophelper\}. We used the R package \{Pophelper\} (https://github.com/royfrancis/pophelper) to

233 build the barplots. We choose as the biologically most relevant $\mathrm{K}$ value the finer population 
234 structure, as the highest $\mathrm{K}$ value for which a new cluster could be identified with individuals

235 highly assigned to it, the new cluster at $\{\mathrm{K}+1\}$ having only admixed individuals (i.e. mean

236 membership coefficient $<0.80$ to the given cluster). For the anther-smut fungus dataset, genetic

237 data were haploidized as individuals were highly homozygous. High homozygosity levels might

238 bias inferences in the software STRUCTURE as these are based on Hardy-Weinberg expectations

239 in a diploid setting (Pritchard et al., 2000). Furthermore, 21 strains were removed, appearing as

240 siblings of other strains, with identical genotypes. Microbotryum fungi have one obligatory

241 sexual event before plant infection, so that clonemates cannot be found in different plants, but

242 high selfing rates may allow the same genotype to be found in neighbor plants if they are

243 parasitized by the same diploid spores or offspring (Giraud, 2004). For the host plant dataset,

244 genetic data were kept as diploid and five individuals were removed as they had identical 245 genotypes as other neighbor plants and may be clonemates. We identified clonemates and

246 siblings in both datasets using the $\operatorname{dist}(\mathrm{X})$ function in the $\mathrm{R}$ package $\{$ Ape $\}$ (Paradis, Claude, \&

247 Strimmer, 2004) and considered two individuals to be siblings if their distance was equal to 0.

248 We then used two methods for assessing population genetic structure that do not assume

249 outcrossing or a lack of linkage disequilibrium. We performed a discriminant analysis of

250 principal components (DAPC) using the R package $\{$ ADEGENET $\}$ (Jombart, 2008; Jombart \&

251 Ahmed, 2011) and used a principal component analysis (PCA) with the dudi.pca function using

252 the R package \{ade4\} (Dray \& Dufour, 2007) on the entire set of individuals in both datasets.

253 Maps showing genotypes per locality were drawn using the R package \{maps\} (Becker, Wilks,

254 Brownrigg, Minka, \& Deckmyn, 2017) and \{mapplots\} (Gerritsen, 2013). Scatter plots were

255 performed using the R package $\{$ ggplot2\} (Wickham, 2009). 
258 We computed, using the R package \{diveRsity\} (Keenan, McGinnity, Cross, Crozier, \& Prodöhl,

259 2016), the following estimates of genetic diversity per locus, site, genetic cluster identified in the

260 STRUCTURE analysis and/or species for the host plants and for the anther-smut fungi datasets:

261 the number of alleles, allelic richness $\left(A_{R}\right)$, observed heterozygosity $\left(H_{O}\right)$, expected

262 heterozygosity $\left(\mathrm{H}_{\mathrm{E}}\right)$, the fixation indexes $\left(\mathrm{F}_{\mathrm{ST}}, \mathrm{F}_{\mathrm{IS}}\right.$ and $\left.\mathrm{F}_{\mathrm{IT}}\right)$, and the Jost's $\mathrm{D}$ statistics

263 corresponding to the fraction of allelic variation found among genetic clusters. We tested whether

264 genotype frequencies fitted the Hardy-Weinberg expectations using a standard $\mathrm{Chi}^{2}$ goodness of

265 fit method and assessed the significance of $\mathrm{F}_{\mathrm{ST}}, \mathrm{F}_{\mathrm{IS}}$ and $\mathrm{F}_{\mathrm{IT}}$ values using a bootstrap procedure

266 with 1000 iterations and calculating 95\% confidence intervals. Sites with less than three sampled

267 individuals were pooled with other sites of the same genetic lineage when they were closer than

268 1/10th of latitude or longitude or were otherwise excluded from the analyses. We excluded nine

269 sites for the plants (site \# 1014, 303, 1532, 719, 1546, 1547, 1437, 429, 1548, 1438) and 13 sites

270 for the fungal pathogens (site \# 1068, 1014, 303, 1532, 719, 1546, 940, 1547, 1437, 333, 1249,

$2716809,1548)$. In total, we considered 20 groups of sites for the host and 19 groups of sites for the

272 pathogen. We included sibling individuals but excluded individuals with admixed membership

273 between genetic clusters inferred from the STRUCTURE analysis (i.e. individuals with mean

274 membership coefficient $<0.80$ to the given cluster), which may be due to low assignment power

275 or admixture. To take into account differences of sample size between sites, we also estimated

276 allelic richness using ADZE (Szpiech, Jakobsson, \& Rosenberg, 2008) which corrects for sample

277 size difference. Calculations were performed using a standardized sample size of $\mathrm{N}=3$,

278 corresponding to the smallest number of observations per site. We tested for mean differences in

279 diversity statistics between species and genetic clusters using a Wilcoxon rank sum test and a

280 Kruskal-Wallis rank sum test in the R software v3.5.3, respectively, considering values across

281 groups of sites. To study isolation-by-distance patterns in the $S$. nutans and fungi parasitizing $S$. 
282 nutans datasets, we computed correlations between matrices of genetic and geographic distances

283 of plant and fungal populations using a Mantel test. Genetic distances between populations at

284 each group of sites were calculated as the Nei's distance (Nei, 1972) using the dist.genpop()

285 function of the R package $\{$ ADEGENET\} (Jombart, 2008; Jombart \& Ahmed, 2011). Geographic

286 distances were calculated using the $\operatorname{distm}()$ function of the R package $\{$ geosphere $\}$. We computed

287 Mantel tests using the mantel.rtest() function of the $\mathrm{R}$ package ade4\} with 1,000,000 resamples

288 for the null distribution. We also studied the correlations between matrices of genetic distances of

289 plant and fungal populations using a Mantel test as above. To remove the effect of the correlation

290 between genetic and geographic distances in the correlation between matrices of genetic

291 distances, we also performed a partial Mantel test using the partial.mantel.test() function of the $\mathrm{R}$

292 package ncf\} with 1,000,000 resamples for the null distribution (Feurtey et al., 2016). We

293 considered 16 group of sites, the same both for the host and the pathogen, corresponding to $S$.

294 nutans host plants and fungal strains belonging to the genetic cluster parasitizing S. nutans. We

295 excluded sites of $S$. italica host plants and fungal strains belonging to the genetic cluster

296 parasitizing S. italica, and one site studied in the host but not studied in the pathogen (site \# 333).

297 We investigated the occurrence of recent events of effective population size reduction (i.e.

298 bottlenecks) within the identified fungal genetic clusters using the program

299 BOTTLENECK version 1.2.02 (Piry, Luikart, \& Cornuet, 1999).

\section{Inference of anther-smut fungi divergence history based on microsatellite markers}

302 We studied the divergence history of the anther-smut fungi sampled on the $S$. nutans lineage

303 complex using an approximate Bayesian computation-random forest (ABC-RF) procedure that

304 performs $\mathrm{ABC}$ inferences based on the machine learning tool named "random forest" (Breiman, 
306 previously inferred (Martin et al., 2016; Martin et al., 2017; Van Rossum et al., 2018). To

307 increase our power to disentangle between different evolutionary scenarios, we performed model

308 choice and parameter estimation by comparing scenarios or groups of scenarios in sequential

309 rounds, each round testing a particular type of evolutionary event, either divergence time, order

310 of divergence or presence of gene flow (Estoup, Raynal, Verdu, \& Marin, 2018; Liu et al., 2019);

311 Table 1; Table S5). We built scenarios based on the genetic clusters obtained using microsatellite

312 markers and on previous analyses of divergence of anther-smut fungi and their host species

313 (Badouin et al., 2017; Gladieux et al., 2013; Martin et al., 2016; Martin et al., 2017; Van Rossum

314 et al., 2018). The tested scenarios varied regarding the time of divergence, the relative order of

315 divergence of fungal genetic clusters and the occurrence of gene flow among genetic fungal

316 clusters (Table S5). We did not include scenarios with variation in effective population sizes as

317 the BOTTLENECK analysis did not identify any signature of effective population size reduction

318 (see 'Results' section). To test if the order of sequential rounds had an effect on the outcome of

319 the analysis, we tested the time of divergence and the relative order of divergence as either the

320 first or the second round (Note S1). We used as populations the fungal genetic clusters identified

321 through population structure analyses and removed fungal strains that were likely siblings of

322 other fungal strains in each genetic cluster.

323 We ran the $\mathrm{ABC}$ procedure modified from (Liu et al., 2019). Briefly, we simulated datasets with

32422 fungal microsatellite markers using the ABCtoolbox program (Wegmann, Leuenberger,

325 Neuenschwander, \& Excoffier, 2010) and used fastsimcoal 2.5 for coalescent-based simulations

326 (Excoffier \& Foll, 2011). We simulated 10,000 genetic datasets per scenario using coalescent

327 simulations with model parameters drawn from prior distributions (Table S6A). We set prior 
328 distributions based on previous analyses of divergence of anther-smut fungi and of their host

329 species (Badouin et al., 2017; Branco et al., 2018; Gladieux et al., 2013; Martin et al., 2016;

330 Martin et al., 2017; Van Rossum et al., 2018). We set a generation time of one year for the

331 pathogen based on its life cycle (Thrall, Biere, \& Antonovics, 1993). We estimated the following

332 parameters: effective size of each genetic cluster $(N)$, divergence time and migration rate per

333 generation between two genetic clusters $x$ and $y$ (Txy and mxy, respectively). We computed 16

334 summary statistics for the observed and simulated datasets with the program arlsumstats (Table

335 S6B; (Excoffier \& Lischer, 2010). We assumed a generalized stepwise model of microsatellite

336 evolution (Estoup, Jarne, \& Cornuet, 2002) and allowed the mutation rate to vary across

337 microsatellite markers. We drew locus-specific mutation rates from a gamma distribution $(\alpha, \alpha / \mu)$

338 in which $\mu$ is the mutation rate per generation and $\alpha$ is a shape parameter (Cornille et al., 2012;

339 Liu et al., 2019). We used the R package \{abcrf\} v1.7.0 (Pudlo et al., 2016) to compute a

340 classification vote through ABC-RF, representing the number of times a scenario was selected

341 among classification $n$ trees of the constructed random forest. We chose $n=500$ trees. For each

342 round, we selected the scenario or group of scenarios with the highest number of classification

343 votes. We computed the posterior probability and the prior error rates over 10 replicated analyses.

344 We performed a linear discriminant analysis (LDA) in the R package $\{$ abcrf $\}$ v1.7.0 (Pudlo et al., 345 2016) on the simulated and observed datasets to visually check the fit of the model to the 346 observed data. Finally, we performed parameter inferences using the group of models eventually 347 selected.

\section{Sequencing data and genome assemblies}

350 We performed whole-genome sequencing for 23 anther-smut fungal strains parasitizing S. italica 
and 30 strains parasitizing S. nutans. Out of these 53 strains, 38 strains belonged to the 170 hostpathogen pairs that were genotyped with microsatellite markers (Table S7). Due to limited fungal material, we sequenced six additional strains that were collected at our studied sites but not genotyped for microsatellite markers and nine additional strains collected at three new sites

355 (Table S7). We extracted DNA from fresh spores stored at $-20^{\circ} \mathrm{C}$ using the Nucleospin Soil Kit 356 (Macherey-Nagel, Germany). Genomes were sequenced using Illumina 150 bp paired-end 357 sequencing technology at $46 \mathrm{X}$ coverage on average. We also included outgroups using available 358 whole-genome sequences of 56 anther-smut fungal strains parasitizing closely-related host

359 species of $S$. nutans and $S$. italica occurring in the studied geographic range (Le Gac, Hood, 360 Fournier, et al., 2007; Refrégier et al., 2008): 33 M. lychnidis-dioicae strains parasitizing $S$.

361 latifolia (Badouin et al., 2017), 19 M. silenes-dioicae strains parasitizing S. dioica (Badouin et al.,

363 (Table S7). We downloaded raw data publicly available from the NCBI SRA under the

364 BioProject IDs PRJNA295022 and PRJEB16741. We thus analysed a total of 109 Microbotryum

365 genomes. For read mapping, we used as reference genome the high-quality haploid genome

366 assembly of the MvSn-1249 M. violaceum s. str. strain corresponding to the $\mathrm{a}_{2}$ mating type

367 (collected on S. nutans) previously obtained with P6/C4 Pacific Biosciences SMRT technology

368 and annotated for gene models (Branco et al., 2017). The MvSn-1249-A2 assembly was accessed

369 from GenBank BioProject accession number PRJEB12080 (BioSample ID: SAMEA3706514, 370 assembly: GCA_900014965).

\section{Genome read mapping and variant calling procedure}

373 We performed read mapping and SNP calling of the 109 analysed genomes against the MvSn374 1249-A2 genome as previously described (Branco et al., 2018; Hartmann, Rodríguez de la Vega, 
375 Brandenburg, Carpentier, \& Giraud, 2018). First, we trimmed Illumina raw reads for sequence

376 quality and removed adapter sequences using the software Cutadapt v1.8.3 (Martin, 2011) with

377 the $\quad$ options: $\quad-\mathrm{q} \quad 10, \quad 10 ; \quad-$ minimum-length $\quad 50 ; \quad$-a

378 AGATCGGAAGAGCACACGTCTGAACTCCAGTCAC;

379 AAGATCGGAAGAGCGTCGTGTAGGGAAAGAGTGTAGATCTCGGTGGTCGCCGTATT.

380 We aligned trimmed reads using the short read aligner bowtie2 v2.1.0 (Langmead, Trapnell, Pop,

381 \& Salzberg, 2009) with the three following software options: -very-sensitive-local; -phred33; -X

382 1000. We removed PCR duplicates using the MarkDuplicates tool of Picard tools version 2.14.1

383 (http://broadinstitute.github.io/picard) and performed local realignment of mapped reads using

384 the tools RealignerTargetCreator and IndelRealigner of the Genome Analysis Toolkit (GATK)

385 version 3.8 (McKenna et al., 2010) to improve alignment accuracy in indel regions. Mean

386 alignment rates to the reference genome ranged from 53 to 96\% (Table S7). For SNP calling, we

387 used GATK version 3.7 (McKenna et al., 2010) and ran HaplotypeCaller on each strain

388 individually using a diploid mode. Then, we used GenotypeGVCFs on a merged gvcf variant file

389 to perform joint variant calls. We filtered SNP calls for quality using VariantFiltration and

390 following the GATK good practices for hard-filtering of variants (QUAL < 250; QD $<2$; MQ $<$

$39130.0 ;-10.5>$ MQRankSum $>10.5 ;-5>$ ReadPosRankSum $>$ 5; FS > 60; SOR > 3) and masked

392 SNPs for repeats. We found 41 SNPs in the strain MvSn-1249-A2 (the very same fungal strain as

393 the reference genome also sequenced with Illumina), indicating low rates of false positives in our

394 SNP calling. We only kept bi-allelic SNPs with a high genotyping rate $(>90 \%)$ on autosomes

395 (i.e., excluding SNPs on the mating-type contigs MvSn-1249-A2-R1_MC15 and MvSn-1249-A2-

396 R1_MC16). We excluded SNPs on the mating-type chromosomes for population genomics

397 analyses as they exhibit suppressed recombination on 90\% of their lengths (Branco et al., 2018).

398 Removing the strain MvSn-1249-A2, we kept 108 fungal strains and 1,305,369 SNPs for 
population genomic analyses.

401 Population genomics analyses

402 To analyze the population genetic structures of anther-smut fungi parasitizing several Silene 403 species using the genome-wide SNP dataset called on autosomes, we used the model-based

404 Bayesian clustering approach implemented in the software STRUCTURE version 2.3.4 405 (Pritchard et al., 2000), from $\mathrm{K}=2$ to $\mathrm{K}=10$ clusters, and performed a PCA, similarly as for the 406 microsatellite datasets. For the STRUCTURE analysis, we selected a set of 233 unlinked SNPs

407 randomly distributed at intervals of $100 \mathrm{~kb}$ along the autosomes, linkage disequilibrium decaying 408 over 50-100 kb in Microbotryum populations (Badouin et al., 2017). We used the R package 409 \{Pophelper\} (https://github.com/royfrancis/pophelper) to perform barplots. We performed the

410 PCA on all SNPs (but excluding missing data and heterozygote genotypes) using the --pca 411 command of the Plink v1.9 software (Chang et al., 2015; Purcell et al., 2007). To study footprints 412 of gene flow between fungal strains, we performed a phylogenetic network analysis implemented 413 in splitsTree (Huson, 1998; Huson \& Bryant, 2006) with the neighbornet method.

417 After checking plant species identity with molecular markers, we retained 145 diseased S. nutans 418 plants and 25 diseased $S$. italica plants (Table S1; Fig 1A). The 21 plant nuclear microsatellite 419 markers distinguished well $S$. nutans and S. italica both in STRUCTURE analyses from K=2 and 420 in the principal component analysis (PCA; Fig 1B-C; Fig S1). 
421 Within S. nutans, we identified four distinct haplotypes based on the six plastid SNPs, retrieving

422 in our sample the four major genetic lineages of $S$. nutans previously identified in Western

423 Europe (Fig 1A; (Martin et al., 2016; Martin et al., 2017; Van Rossum et al., 2018). The blue,

424 yellow, orange, and red haplotypes were found, as in previous studies, in the northeastern,

425 southeastern, western and southwestern parts of Europe, respectively. All S. italica samples had a

426 blue plastid haplotype (Fig 1A). Within S. nutans, the PCA based on the 21 plant nuclear

427 microsatellite markers mainly differentiated the orange genetic lineage from the other ones (Fig

428 1B; Fig S1B) and the STRUCTURE analysis detected four genetic clusters, corresponding to the

429 different plastid haplotypes, except for the red haplotype for which we had too few samples (Fig

430 1C; Fig S1A). The STRUCTURE analysis further identified two well-separated genetic clusters

431 within the $S$. nutans orange plastid haplotype (Fig. 1C). These two genetic clusters also appeared

432 separated on the second axis of the PCA and corresponded to plant individuals collected in the

433 Northern part of France versus Belgium and Western part of France (Fig S1), in agreement with

434 previous findings (Martin et al., 2016). From the STRUCTURE analyses, we identified five host

435 individuals with admixed cluster memberships (mean membership coefficient $<0.80$ to the given

436 cluster), which may be due to low assignment power or admixture between genetic clusters. We

437 found no further clear subdivision within $S$. nutans at higher K values and no clear population

438 subdivision within $S$. italica (Fig S1A).

439 We found no significant differences in allelic richness neither between $S$. nutans and S. italica

440 (Wilcoxon rank sum (WRS) test on 20 groups of sites, $\mathrm{W}=12$, $\mathrm{p}$-value $=0.169$; Table S8A) nor

441 between the four $S$. nutans genetic clusters (Kruskal-Wallis rank sum (KWRS) test on 16 groups

442 of sites, $\mathrm{Chi}^{2}=4.92$, degree of freedom $(\mathrm{df})=3$, $\mathrm{p}$-value $=0.178$; Table S8A). In $S$. nutans, levels

443 of observed heterozygosity were significantly lower than those of expected heterozygosity under 
444 Hardy-Weinberg equilibrium for most loci, the mean $\mathrm{F}_{\text {IS }}$ value per marker being 0.33 (Table S2).

445 In $S$. italica, levels of observed and expected heterozygosities were not significantly different for 446 most markers (78\%; Table S2), the mean $\mathrm{F}_{\mathrm{IS}}$ value per locus being 0.37 (Table S2). As expected,

447 pairwise $\mathrm{F}_{\mathrm{ST}}$ and Jost's D indicated higher divergence between $S$. italica and $S$. nutans (mean $448 \quad \mathrm{~F}_{\mathrm{ST}}=0.32$; mean Jost's $\mathrm{D}=0.57$; Table $\mathrm{S} 9 \mathrm{~A}$ ) than between genetic clusters of $S$. nutans (mean $449 \mathrm{~F}_{\mathrm{ST}}=0.20$; mean Jost's $\mathrm{D}=0.35$; Table S9A; KWRS test for both statistics, $\mathrm{W}=0$, p-value $=$ 450 0.010). For S. nutans, we found on average lower pairwise F $F_{\mathrm{ST}}$ and Jost's D values between the 451 yellow Western cluster and the two orange Western and Northwestern genetic clusters (mean $452 \mathrm{~F}_{\mathrm{ST}}=0.17$; mean Jost's $\mathrm{D}=0.28$; Table S9A) than between the blue Eastern genetic cluster and the 453 Western genetic clusters (mean $\mathrm{F}_{\mathrm{ST}}=0.24$; mean Jost's $\mathrm{D}=0.42$; Table $\mathrm{S} 9 \mathrm{~A}$ ), although the 454 difference was not significant (KWRS test for $\mathrm{F}_{\mathrm{ST}}, \mathrm{W}=8$, p-value $=0.200$; KWRS test for Jost's $455 \mathrm{D}, \mathrm{W}=9, \mathrm{p}$-value $=0.100)$. The correlation between the matrices of pairwise genetic and 456 geographic distances for $S$. nutans (tested on 16 sites) was significantly positive (Mantel test: $\mathrm{r}=$ $4570.54, \mathrm{p}$-value $<0.001)$, indicating an isolation-by-distance pattern.

460 Population genetic structure analyses separated Microbotryum strains into two main genetic 461 clusters, corresponding to their host plant of sampling, S. italica and S. nutans. The host of 462 collection separated strains according to the first axis of the PCA (Fig 2B). The STRUCTURE 463 analysis and the discriminant analysis of principal component (DAPC) also delimitated two clear

464 fungal genetic clusters according to the host of sampling at $\mathrm{K}=2$ (Fig 2C; Fig S2). In the PCA 465 (Fig. 2B), four Microbotryum strains sampled on S. nutans clustered with strains parasitizing $S$. 
italica and one Microbotryum strain sampled on S. italica clustered with strains parasitizing $S$.

467 nutans. These strains may correspond to spill-overs, i.e. cross-species disease transmissions,

468 between the two studied Silene species or from other Silene species. We excluded for further

469 analyses the 11 strains that had their main cluster memberships $<80 \%$ in the STRUCTURE

470 analysis at $\mathrm{K}=2$ (Fig 2C), which can be due to low assignment power or admixture.

471 Anther-smut fungi parasitizing S. italica had on average higher levels of allelic richness (WRS

472 test on 19 groups of sites, $\mathrm{W}=48, \mathrm{p}$-value $=0.004)$ and observed heterozygosity (WRS test on

47319 groups of sites, $\mathrm{W}=30, \mathrm{p}$-value $=0.014)$ than anther-smut fungi parasitizing $S$. nutans (Table

474 S8B). Levels of observed heterozygosity were significantly lower than heterozygosity expected

475 under Hardy-Weinberg equilibrium for eight markers for Microbotryum fungi parasitizing $S$.

476 nutans and six markers for Microbotryum fungi parasitizing S. italica (Table S4).

478 Similar genetic structure in anther-smut fungi as in their Silene nutans and S. italica host

\section{9 plants}

480 The existence of additional levels of population genetic structure within fungal strains was

481 indicated by the STRUCTURE barplots (Fig S2), the second and third principal components of

482 the PCA that explained $27.9 \%$ of the total variance between strains (Fig 2B). To investigate the

483 population structure within each of the two main genetic clusters of anther-smut fungi,

484 corresponding mainly to populations parasitizing $S$. nutans and $S$. italica, respectively, we

485 analyzed them separately, which confirmed the existence of a strong population structure within

486 anther-smut fungi parasitizing S. nutans (Fig 3A). The first two PCA axes separated fungal

487 strains into three distinct genetic clusters, corresponding to the three most frequent plastid 
491 nutans host plastid haplotypes. In contrast to the host plant $S$. nutans, we found no clear 492 subdivision in the orange Western anther-smut fungal cluster (Fig S3). We found no genetic 493 clusters specific to strains sampled from a host with a red haplotype, perhaps due to the low strain 494 number. We excluded for further analyses the two admixed fungal strains (cluster memberships $495<0.80$ in a given cluster) and the three fungal strains sampled on a host with a red haplotype. We

496 found no further population structure in the set of 28 anther-smut strains parasitizing S. italica 497 (Fig S4), as for the host plant.

498 All three fungal genetic clusters parasitizing S. nutans had similar levels of allelic richness

499 (KWRS test on 16 groups of sites, $\mathrm{Chi}^{2}=1.33, \mathrm{df}=2$, $\mathrm{p}$-value $=0.514$; Table $\left.\mathrm{S} 8 \mathrm{~B}\right)$ and observed 500 heterozygosity $\left(\mathrm{KWRS}\right.$ test, $\mathrm{Chi}^{2}=0.67 \mathrm{df}=2, \mathrm{p}$-value $=0.716$; Table $\left.\mathrm{S} 8 \mathrm{~B}\right)$. The $\mathrm{F}_{\text {IS }}$ varied 501 between genetic clusters from -0.11 to 0.82 (Table S8B). We found no significant differences in 502 differentiation between the three fungal genetic clusters (KWRS tests for $\mathrm{F}_{\mathrm{ST}}$ and Jost's D, Chi ${ }^{2}=$ $5032, \mathrm{df}=2, \mathrm{p}$-value $=0.368 ;$ Table S9B). The significant correlation between the matrices of 504 genetic and geographic distances between pairs of fungal populations parasitizing S. nutans (16 505 sites) indicated an IBD pattern (Mantel test: $r=0.62$, $p$-value $<0.001$ ). There was a significantly 506 positive correlation between genetic distance matrices for the fungal and the $S$. nutans 507 populations (16 sites; Mantel test: $\mathrm{r}=0.80$, $\mathrm{p}$-value $<0.001$ ), and it remained significant when 508 controlling for the IBD effect (partial Mantel test: $r=0.70$, p-value $<0.001$ ). Altogether, our 509 findings indicate strong congruence between the population genetic structures of the anther-smut 510 fungi parasitizing $S$. nutans and its host plant $S$. nutans (Fig 3C). We found no signatures of 
511 recent reduction in effective population size in either of the three fungal genetic clusters

512 parasitizing $S$. nutans nor the fungal genetic cluster parasitizing $S$. italica using the 513 BOTTLENECK software (Piry et al., 1999) under either stepwise or two-phase models of 514 microsatellite evolution (Table S10; one-tailed Wilcoxon signed rank test, all P-values $>0.36$ ).

516 Inferred divergence history of anther-smut fungi on Silene nutans congruent with of their

517 host plant

518 To study if the anther-smut fungi on S. nutans shared the same history of divergence into cryptic

519 lineages as the one previously inferred for their host plants, the $S$. nutans cryptic species complex

520 (Martin et al., 2016; Martin et al., 2017; Van Rossum et al., 2018), we used an approximate

521 Bayesian computation random forest (ABC-RF) procedure. We compared various divergence

522 scenarios for the three identified Microbotryum genetic clusters parasitizing S. nutans. We

523 removed the 21 fungal strains that were likely siblings of other fungal strains, keeping 110

524 anther-smut fungal strains belonging to the blue Eastern, yellow Western and orange Western

525 Microbotryum genetic clusters parasitizing $S$. nutans and we used as outgroup the 25 genotyped

526 Microbotryum strains parasitizing S. italica.

527 We performed three rounds of scenario comparison, each testing a particular evolutionary event, 528 including divergence times, divergence order and the occurrence of gene flow (Table 1; Table S5;

529 Fig S5). At each round, we retained the inferred most likely evolutionary scenario to be used as 530 backbone for the subsequent rounds. To assess our power to discriminate between scenarios, we 531 checked posterior probability (Table 1) and assessed visually whether the observed data fell 532 within the clouds of simulated data of the compared scenarios (Fig S6). 
533 In the first round ("time of divergence"; Table 1, "round 1"), we tested four different time periods

534 of divergence for various divergence orders (A, B or C; Fig S5A). The group of scenarios with

535 strongest support included a first divergence occurring between 100,000-1,500,000 years ago,

536 and a second divergence occurring between 0-20,000 years ago (posterior probability $=0.54+-$

5370.02 , prior error rate $=34 \%$; Table 1, "round 1"; Fig S6A). In the second round ("divergence

538 order"; Table 1, "round 2"), we found with a high posterior probability for the scenario assuming

539 a first divergence of the blue Eastern Microbotryum genetic cluster, followed by the divergence

540 between the yellow and orange Western Microbotryum genetic clusters (posterior probability =

$5410.79+-0.02$, prior error rate $=2 \%$; Table 1, "round 2"; Fig S6B). When testing the order of

542 divergence between clusters as first round and the time of divergence as second round, we

543 selected the same scenarios with a high posterior probability (Note S1; Table S11).

544 In the third round ("occurrence of gene flow"; Table 1, "round 3, step 1"), we compared in a first

545 step three groups of scenarios differing in the clusters affected by gene flow. The most supported

546 group of scenarios assumed gene flow among Microbotryum genetic clusters parasitizing $S$.

547 nutans but not with $S$. italica (posterior probability $=0.60+-0.02$, prior error rate $=5 \%$; Table 1 ,

548 "round 3, step 1"; Fig S6C). In the following steps (Table 1, "round 3, steps 2 to 4"), we

549 compared groups of scenarios of divergence with different timing of gene flow. Scenarios of

550 divergence with ancient gene flow were the most supported, which suggested that episodes of

551 ancient gene flow occurred during divergence or just following divergence of the three

552 Microbotryum genetic clusters parasitizing S. nutans and then completely stopped (posterior

553 probability $=0.76+-0.02$, prior error rate $=35 \%$; Table 1, "round 3, step 2"; Fig S6D-F).

554 However, we did not have enough power to differentiate between scenarios of ancient gene flow

555 that involved different genetic clusters (either all three genetic clusters or only the two Western 
556 genetic clusters) or different times of past gene flow (either over a 0-20000 year period or a

$55750,000-500,000$ year period; Table S5; posterior probability $=0.49+-0.03$, prior error rate $=60 \%$;

558 Table 1, "round 3, step 5"). We performed parameter inferences for the group of four models

559 with ancient migration ("round 3, step 2", group 3 see Table 1; Table S12). The inferred dates

560 and order of divergence between fungal genetic clusters parasitizing S. nutans were consistent

561 with the history of divergence previously inferred for the host plant S. nutans (Fig 4; Martin et

562 al., 2016; Martin et al., 2017; Van Rossum et al., 2018).

564 No genome-wide signatures of gene flow between anther-smut fungi on distinct Silene 565 species

566 To check whether genome-wide data support the patterns inferred above on population genetic

567 structure in the anther-smut fungi and lack of recent gene flow, we sequenced the genomes of 53

568 Microbotryum strains parasitizing S. nutans or S. italica (Table S7). We also used previously

569 sequenced genomes of anther-smut fungi parasitizing species with overlapping geographical

570 ranges in order to check if some of the strains that appeared as admixed or did not cluster

571 according to their host species may actually correspond to other Microbotryum species. After

572 filtration, we obtained 1,305,369 SNPs for 108 Microbotryum strains. We performed PCA

573 analyses on the genome-wide SNPs and STRUCTURE analyses and confirmed strong population

574 differentiation between fungal strains parasitizing S. nutans and S. italica (Fig 5A-B; Fig S7A).

575 Only one strain parasitizing $S$. nutans clustered with strains parasitizing $S$. italica, similarly as

576 found from microsatellite data (strain \# 1438; Fig 2C), therefore likely being a genuine spill-over

577 between $S$. nutans and S. italica. Two other strains parasitizing S. nutans clustered with strains 
578 parasitizing S. latifolia. These strains had admixed cluster membership (i.e. mean membership

579 coefficient $<0.80$ to the given cluster) or clustered with strains parasitizing $S$. italica from

580 microsatellite data (Fig 2C). These strains likely represent spill-overs between S. nutans and $S$.

581 latifolia.

582 Genome sequences retrieved the same genetic structure as microsatellites for anther-smut fungi

583 parasitizing $S$. nutans, with a strong differentiation between Microbotryum strains sampled on the

$584 S$. nutans blue plastid haplotype on the one hand and those sampled on yellow, red or orange

585 plastid haplotypes on the other hand (Fig S7B), and confirmed the absence of strong population

586 structure within anther-smut fungi parasitizing S. italica (Fig S7C). We also found strong

587 population differentiation between fungal strains parasitizing the three closely related host

588 species of $S$. nutans and S. italica (Fig 5A-B). STRUCTURE analyses showed no signatures of

589 recent admixture between strains parasitizing different hosts (Fig 5B).

590 The phylogenetic network analysis implemented in SplitsTree also supported the absence of

591 recent gene flow at the genome-wide levels between the Microbotryum species parasitizing

592 different hosts and the close genetic similarity of the three genetic clusters of anther-smut fungi

593 parasitizing the $S$. nutans complex (Fig 5C). Within Microbotryum strains parasitizing S. nutans,

594 we found no footprint of recombination between strains of the two main genetic clusters (Fig 5C)

595 which was consistent with a scenario of divergence with ancient migration and no contemporary

596 gene flow inferred from ABC demographic inferences. 
599 We found that genetic structure and divergence history of anther-smut fungi parasitizing the $S$. 600 nutans plant species complex closely mirrored those of their host plant genetic lineages. Such a 601 congruence in population structure and divergence history of the host and the pathogen in the $S$. 602 nutans complex, the distribution area of the genetic clusters in Western Europe, as well as the 603 inferred dates of divergence suggest that the host and the pathogen differentiated in parallel 604 following isolation in shared glacial refugia. To confirm the co-divergence events between $S$. 605 nutans lineages and anther-smut fungi genetic clusters, we need to more accurately date the node 606 of lineage divergence events in the host and the pathogen. Such molecular dating is essential to 607 support co-divergence events as preferential shifts of the pathogen to closely related host species 608 can also produce congruent phylogenies (de Vienne et al., 2013), but is currently difficult due 609 lack of appropriate calibration points.

610 Nevertheless, our results rule out the hypothesis that anther-smut fungi on some of the $S$. nutans 611 genetic lineages may result from specialization by host shifts from distant anther-smut fungi 612 parasitizing other Silene species in sympatry or parapatry. This contrasts with the prevalence of 613 host shifts between distant lineages observed in the Caryophyllaceae-Microbotryum system at 614 larger evolutionary scales (Refrégier et al., 2008), but is consistent with the strong congruence 615 reported between the population genetic structures of $S$. latifolia and its anther-smut fungi, also 616 corresponding to glacial refugia footprints (Feurtey et al., 2016). Our study thus contributes to 617 gain general insights into the processes of divergence in host-pathogen systems. While at large 618 evolutionary scales, host shifts seem to be the rule (de Vienne, Hood, \& Giraud, 2009; Thines, 619 2019), finer and more recent population subdivisions may more often result from codivergence 620 due to shared geographic and climatic constraints, such as glacial refugia. The discrepancy 621 between the two evolutionary scales may be due to recurrent pathogen lineage extinctions 
622 followed by recolonizations through host shifts: codivergence may occur frequently, but

623 pathogen lineages would regularly go extinct over longer evolutionary scales and plant lineages

624 would be recolonized by host shifts. This novel hypothesis can be tested by studying further

625 closely related pairs of natural host-pathogen associations, which unfortunately still remain

626 scarce.

627 The significant IBD pattern in both the S. nutans plant and anther-smut fungi and the correlation

628 between the genetic distances between host and pathogen pairs when controlling for IBD suggest

629 that the anther-smut fungi followed similar recolonization routes as the plant and/or became

630 specialized on the host genetic lineages. However, contrary to the system S. latifolia - M.

631 lychnidis-dioicae (Feurtey et al., 2016) and other host-pathogen systems (Barrett et al., 2008;

632 Criscione, Poulin, \& Blouin, 2005; Nieberding et al., 2008; Nieberding \& Olivieri, 2007), we

633 found higher levels of subdivision in $S$. nutans than in its associated anther-smut fungi. The

634 weaker genetic structure in anther smut fungi compared to its host suggests again extinction of

635 the pathogen lineage in a plant lineage, followed by recolonization from another fungal lineage,

636 or the ability of an anther-smut lineage to remain generalist on two closely related plant lineages.

637 Future studies using cross-inoculation experiments between strains and host plants of different

638 genetic clusters within the $S$. nutans complex could assess whether the congruence of host-

639 pathogen genetic structure is associated with a pattern of local adaptation of the pathogen or of

640 the pathogen, as in the system S. latifolia - M. lychnidis-dioicae (Delmotte et al., 1999; Feurtey et

641 al., 2016; Kaltz et al., 1999). We could not obtain enough fresh material for this study to be able

642 to test local adaptation. Furthermore, strong asymmetric postzygotic reproductive isolation was

643 found between the Eastern and Western S. nutans plant lineages (Martin et al., 2017) and it would

644 be interesting in future studies to explore if a similar reproductive isolation pattern is present 
645 between the Eastern and Western fungal lineages on S. nutans, and whether reproductive

646 isolation can be found among anther-smut fungi.

647 We found clear differentiation between fungal populations parasitizing the two closely related $S$.

648 nutans and $S$. italica species, supporting previous findings of differentiation based on a few

649 strains and loci (Bucheli et al., 2000). No strong population structure was found within S. italica

650 or within its associated anther-smut fungi. However, future studies with larger sampling

651 distribution in the $S$. italica range in the Mediterranean Basin (Naciri, Pasquier, Lundberg,

652 Jeanmonod, \& Oxelman, 2017) may identify population differentiation. Cross-species disease

653 transmissions, i.e. spill-overs of fungal strains, were more frequent on S. nutans than on S. italica,

654 which may be due to unequal sampling size between the two Silene species or to biological

655 differences. Some Caryophyllaceae plants indeed seem more susceptible to cross-species

656 transmissions (Antonovics et al., 2002; de Vienne, Hood, et al., 2009; Hood et al., 2019). Putative

657 spill-overs may actually correspond to other Microbotryum species, that were too rare to be

658 identified in our population analyses using microsatellite markers, as revealed with the whole

659 genome sequence data. In fact, two strains collected on S. nutans were actually assigned, based

660 on whole genome sequences, to M. lychnidis-dioicae, specialized on S. latifolia.

661 The statistical comparison of demographic models and the whole-genome SNP analyses indicated

662 the absence of recent gene flow between Microbotryum species parasitizing closely related Silene

663 species, as well as between the Eastern and Western fungal lineages parasitizing S. nutans,

664 although some spill-over cases were detected. Noteworthy, we also found no evidence of hybrid

665 individuals between the two host plants species $S$. nutans and $S$. italica based on SNP data. The

666 admixed barplots observed in the microsatellite STRUCTURE analyses must therefore have been

667 due to low power of assignment rather than recent hybridization. This result was consistent with 
668 previous studies on other several anther-smut fungi, in which no hybrids were detected in natural

669 populations, even between very closely related species that can hybridize in the laboratory

670 (Abbate et al., 2018; Badouin et al., 2017; Gladieux et al., 2013; Petit et al., 2017). The only case

671 where hybrids were detected was among closely related anther-smut fungi with overlapping host

672 and geographic ranges, on Dianthus species (Petit et al., 2017). Ecological factors, such as

673 different habitats, pollinator guilds or flowering time of the host species (Jürgens, Witt, \&

674 Gottsberger, 1996; Kephart, Reynolds, Rutter, Fenster, \& Dudash, 2006), may constitute pre-

675 zygotic factors favoring reproductive isolation of host-specialized anther-smut fungi in natural

676 populations. Both extrinsinc and intrinsic post-zygotic barriers can be strong in anther-smut fungi

677 (Giraud \& Gourbière, 2012; Le Gac, Hood, \& Giraud, 2007). Strong host specialization may

678 indeed play a role in reproductive isolation, through migrant inviability and hybrid maladaptation

679 on parental hosts, especially given the life cycle of Microbotryum fungi, with many spores falling

680 on a plant and competing for systemic infection, and selfing being frequent, exposing hybrids to

681 systematic competition with non-hybrids (Gibson, Hood, \& Giraud, 2012). In addition,

682 comparative genomics of anther-smut fungi showed presence of large genomic rearrangements

683 and gene content variation between species (Branco et al., 2018; Hartmann et al., 2018), and

684 experimental crosses suggested high frequency of hybrid sterility and abnormal genomic contents

685 in hybrids (de Vienne, Refrégier, et al., 2009).

686 The low levels of gene flow among anther-smut fungi parasitizing different hosts found in

687 Microbotryum fungi stand in high contrast with frequent reports of signatures of introgression in

688 other fungal pathogens, such as crop pathogens or human disease-associated pathogens (Feurtey

$689 \&$ Stukenbrock, 2018). Few studies have focused on fungal pathogens diversification in natural

690 host communities while several evolutionary processes, such as time scale of divergence, host 
691 density and heterogeneity, are likely very different than those occurring on human-modified

692 environment pathogens (Laine, 2005; Laine, Barrès, Numminen, \& Siren, 2019; Stukenbrock \&

693 McDonald, 2008). To understand how biodiversity arises and what the mechanisms of host-

694 pathogen evolution are over large evolutionary scales, we need more studies on co-evolutionary

695 histories of parasites and their hosts in natural ecosystems. Studies of population genetic structure

696 and divergence in plant fungal pathogens indeed remain so far mostly focused on crop pathogens

697 (Barrès et al., 2008; Enjalbert, Duan, Leconte, HovmøLler, \& De Vallavieille-Pope, 2005;

698 Fournier \& Giraud, 2008; Linde, Zhan, \& McDonald, 2002; Saleh, Milazzo, Adreit, Fournier, \&

699 Tharreau, 2014; Stukenbrock, Banke, \& McDonald, 2006; Zaffarano, McDonald, \& Linde,

700 2008), in which patterns are heavily impacted by host genetic homogeneity and high abundance,

701 as well as by human-mediated plant and pathogen dispersal. We found here strong population

702 structure congruence between hosts and pathogens, in agreement with a previous study on other

703 anther-smut lineages (Feurtey et al., 2016). Further studies on other natural systems are needed to

704 assess whether this represents a general pattern in natural pathogen-host communities.

\section{Acknowledgements}

707 We thank all the collectors cited in Table S1 and S7 for their contribution to plant material

708 sampling, the Département de la Nature et des Forêts (Service Public de Wallonie, Belgium), B.

709 Clesse (Centre Marie-Victorin, Cercles des Naturalistes de Belgique asbl), Ardenne \& Gaume

710 and Natagora for access to natural sites and for the authorization to collect plant material. We are

711 grateful to the INRA MIGALE bioinformatics platform (http://migale.jouy.inra.fr) for providing

712 computational resources and the Genotoul platform for sequencing. We thank the Plateforme de

713 Genotypage GENTYANE INRA UMR1095 for help with microsatellite genotyping. This work 
was supported by the European Research Council (ERC) (starting grant GenomeFun 309403), the

715 French National Research Agency (ANR) (Gandalf ANR Grant ANR-12-ADAP-0009), the Louis

0013) to FEH. PT and CG thank the Région Hauts-de-France, and the Ministère de

\section{Datasets}

dataset 1: Hartmann F.E., Snirc A., Cornille A., Godé C., Touzet P., Van Rossum F., Fournier E., Le Prieur S., Shykoff J., Giraud T. 2019. Plant microsatellite and chloroplastic genotypes. Dryad doi (to be completed upon acceptance). Le Prieur S., Shykoff J., Giraud T. 2019. Fungal microsatellite genotypes. Dryad doi (to be completed upon acceptance).

\section{References}

Abbate, J. L., Gladieux, P., Hood, M. E., de Vienne, D. M., Antonovics, J., Snirc, A., \& Giraud, host species. Molecular Ecology, 27(16), 3357-3370. doi: 10.1111/mec.14805

Antonovics, J., Hood, M. E., \& Partain, J. (2002). The ecology and genetics of a host shift: Microbotryum as a model system. The American Naturalist, 160(S4), S40-S53. doi: $10.1086 / 342143$

Badouin, H., Gladieux, P., Gouzy, J., Siguenza, S., Aguileta, G., Snirc, A., ... Giraud, T. (2017). Widespread selective sweeps throughout the genome of model plant pathogenic fungi and 
identification of effector candidates. Molecular Ecology, 26(7), 2041-2062. doi: 10.1111/mec. 13976

Barrès, B., Halkett, F., Dutech, C., Andrieux, A., Pinon, J., \& Frey, P. (2008). Genetic structure of the poplar rust fungus Melampsora larici-populina: Evidence for isolation by distance in Europe and recent founder effects overseas. Infection, Genetics and Evolution, 8(5), 577-587. doi: 10.1016/j.meegid.2008.04.005

Barrett, L. G., Thrall, P. H., Burdon, J. J., \& Linde, C. C. (2008). Life history determines genetic structure and evolutionary potential of host-parasite interactions. Trends in Ecology \& Evolution, 23(12), 678-685. doi: 10.1016/j.tree.2008.06.017

Becker, R., Wilks, A., Brownrigg, R., Minka, T., \& Deckmyn, D. (2017). maps: draw geographical maps. $R$ package version 3.2.0. (https://cran.rproject.org/web/packages/maps/index.html).

Bernasconi, G., Antonovics, J., Biere, A., Charlesworth, D., Delph, L. F., Filatov, D., ... Widmer, A. (2009). Silene as a model system in ecology and evolution. Heredity, 103(1), 5-14. doi: 10.1038/hdy.2009.34

Branco, S., Badouin, H., Rodríguez de la Vega, R. C., Gouzy, J., Carpentier, F., Aguileta, G., ... Giraud, T. (2017). Evolutionary strata on young mating-type chromosomes despite the lack of sexual antagonism. Proceedings of the National Academy of Sciences, 114(27), 7067-7072. doi: 10.1073/pnas.1701658114

Branco, S., Carpentier, F., Rodríguez de la Vega, R. C., Badouin, H., Snirc, A., Prieur, S. L., ... Giraud, T. (2018). Multiple convergent supergene evolution events in mating-type chromosomes. Nature Communications, 9(1), 2000. doi: 10.1038/s41467-018-04380-9

Breiman, L. (2001). Random forests. Machine Learning, 45(1), 5-32. doi: 10.1023/A:1010933404324

Bucheli, E., Gautschi, B., \& Shykoff, J. A. (2000). Host-specific differentiation in the anther smut fungus Microbotryum violaceum as revealed by microsatellites. J. EVOL. BIOL., 11.

Chang, C. C., Chow, C. C., Tellier, L. C., Vattikuti, S., Purcell, S. M., \& Lee, J. J. (2015). Second-generation PLINK: rising to the challenge of larger and richer datasets. GigaScience, 4(1). doi: 10.1186/s13742-015-0047-8

Cornille, A., Gladieux, P., Smulders, M. J. M., Roldán-Ruiz, I., Laurens, F., Le Cam, B., ... Giraud, T. (2012). New insight into the history of domesticated apple: Secondary contribution of the European wild apple to the genome of cultivated varieties. PLOS Genetics, 8(5), e1002703. doi: 10.1371/journal.pgen.1002703

Criscione, C. D., Poulin, R., \& Blouin, M. S. (2005). Molecular ecology of parasites: elucidating ecological and microevolutionary processes. Molecular Ecology, 14(8), 2247-2257. doi: 10.1111/j.1365-294X.2005.02587.x

Croll, D., \& Laine, A.-L. (2016). What the population genetic structures of host and pathogen tell us about disease evolution. New Phytologist, 212(3), 537-539. doi: 10.1111/nph.14203

de Vienne, D. M., Hood, M. E., \& Giraud, T. (2009). Phylogenetic determinants of potential host shifts in fungal pathogens. Journal of Evolutionary Biology, 22(12), 2532-2541. doi: 10.1111/j.1420-9101.2009.01878.x

de Vienne, D. M., Refrégier, G., Hood, M. E., Guigue, A., Devier, B., Vercken, E., ... Giraud, T. (2009). Hybrid sterility and inviability in the parasitic fungal species complex Microbotryum. Journal of Evolutionary Biology, 22(4), 683-698. doi: 10.1111/j.14209101.2009.01702.x

de Vienne, D. M., Refrégier, G., López-Villavicencio, M., Tellier, A., Hood, M. E., \& Giraud, T. (2013). Cospeciation vs host-shift speciation: methods for testing, evidence from natural 
associations and relation to coevolution. New Phytologist, 198(2), 347-385. doi: 10.1111/nph. 12150

Delmotte, F., Bucheli, E., \& Shykoff, J. A. (1999). Host and parasite population structure in a natural plant-pathogen system. Heredity, 82(3), 300-308. doi: 10.1046/j.13652540.1999.00485.x

Dray, S., \& Dufour, A.-B. (2007). The ade4 Package: Implementing the Duality Diagram for Ecologists. Journal of Statistical Software, 22(1), 1-20. doi: 10.18637/jss.v022.i04

Dybdahl, M. F., \& Lively, C. M. (1996). The geography of coevolution: comparative population structures for a snail and its trematode parasite. Evolution, 50(6), 2264-2275. doi: 10.1111/j.1558-5646.1996.tb03615.x

Enjalbert, J., Duan, X., Leconte, M., HovmøLler, M. S., \& De Vallavieille-Pope, C. (2005). Genetic evidence of local adaptation of wheat yellow rust (Puccinia striiformis $\mathrm{f}$. sp. tritici) within France. Molecular Ecology, 14(7), 2065-2073. doi: 10.1111/j.1365294X.2005.02566.x

Estoup, A., Jarne, P., \& Cornuet, J.-M. (2002). Homoplasy and mutation model at microsatellite loci and their consequences for population genetics analysis. Molecular Ecology, 11(9), 1591-1604. doi: 10.1046/j.1365-294X.2002.01576.x

Estoup, A., Raynal, L., Verdu, P., \& Marin, J.-M. (2018). Model choice using Approximate Bayesian Computation and Random Forests: analyses based on model grouping to make inferences about the genetic history of Pygmy human populations | Journal de la Société Française de Statistique. Special Issue on Models and Inference in Population Genetics, 159(3). Retrieved from http://journal-sfds.fr/article/view/709

Excoffier, L., \& Foll, M. (2011). fastsimcoal: a continuous-time coalescent simulator of genomic diversity under arbitrarily complex evolutionary scenarios. Bioinformatics, 27(9), 13321334. doi: 10.1093/bioinformatics/btr124

Excoffier, L., \& Lischer, H. E. L. (2010). Arlequin suite ver 3.5: a new series of programs to perform population genetics analyses under Linux and Windows. Molecular Ecology Resources, 10(3), 564-567. doi: 10.1111/j.1755-0998.2010.02847.x

Feurtey, A., Gladieux, P., Hood, M. E., Snirc, A., Cornille, A., Rosenthal, L., \& Giraud, T. (2016). Strong phylogeographic co-structure between the anther-smut fungus and its white campion host. New Phytologist, 212(3), 668-679. doi: 10.1111/nph.14125

Feurtey, A., \& Stukenbrock, E. H. (2018). Interspecific gene exchange as a driver of adaptive evolution in fungi. Annual Review of Microbiology, 72(1), 377-398. doi: 10.1146/annurev-micro-090817-062753

Fisher, M. C., Gow, N. A. R., \& Gurr, S. J. (2016). Tackling emerging fungal threats to animal health, food security and ecosystem resilience. Phil. Trans. R. Soc. B, 371(1709), 20160332. doi: 10.1098/rstb.2016.0332

Fortuna, T. M., Snirc, A., Badouin, H., Gouzy, J., Siguenza, S., Esquerre, D., ... Giraud, T. (2016). Polymorphic microsatellite markers for the tetrapolar anther-smut fungus Microbotryum saponariae based on genome sequencing. PLOS ONE, 11(11), e0165656. doi: 10.1371/journal.pone.0165656

Fournier, E., \& Giraud, T. (2008). Sympatric genetic differentiation of a generalist pathogenic fungus, Botrytis cinerea, on two different host plants, grapevine and bramble. Journal of Evolutionary Biology, 21(1), 122-132. doi: 10.1111/j.1420-9101.2007.01462.x

Gandon, S., \& Michalakis, Y. (2002). Local adaptation, evolutionary potential and host-parasite coevolution: interactions between migration, mutation, population size and generation time. Journal of Evolutionary Biology, 15(3), 451-462. doi: 10.1046/j.1420- 
Gandon, S., Capowiez, Y., Dubois, Y., Michalakis, Y., \& Olivieri, I. (1996). Local adaptation and gene-for-gene coevolution in a metapopulation model. Proceedings of the Royal Society of London. Series B: Biological Sciences, 263(1373), 1003-1009. doi: 10.1098/rspb.1996.0148

Gerritsen, H. (2013). Mapplots, $r$ package version 1.5. https://CRAN.Rproject.org/package $=$ mapplots.

Gibson, A. K., Hood, M. E., \& Giraud, T. (2012). Sibling competition arena: selfing and a competition arena can combine to constitute a barrier to gene flow in sympatry. Evolution, 66(6), 1917-1930. doi: 10.1111/j.1558-5646.2011.01563.x

Giraud, T. (2004). Patterns of within population dispersal and mating of the fungus Microbotryum violaceum parasitising the plant Silene latifolia. Heredity, 93(6), 559-565. doi: $10.1038 /$ sj.hdy.6800554

Giraud, T., \& Gourbière, S. (2012). The tempo and modes of evolution of reproductive isolation in fungi. Heredity, 109(4), 204-214. doi: 10.1038/hdy.2012.30

Giraud, T., Yockteng, R., Marthey, S., Chiapello, H., Jonot, O., Lopez-Villavicencio, M., ... Dossat, C. (2008). Isolation of 60 polymorphic microsatellite loci in EST libraries of four sibling species of the phytopathogenic fungal complex Microbotryum. Molecular Ecology Resources, 8(2), 387-392. doi: 10.1111/j.1471-8286.2007.01967.x

Gladieux, P., Devier, B., Aguileta, G., Cruaud, C., \& Giraud, T. (2013). Purifying selection after episodes of recurrent adaptive diversification in fungal pathogens. Infection, Genetics and Evolution: Journal of Molecular Epidemiology and Evolutionary Genetics in Infectious Diseases, 17, 123-131. doi: 10.1016/j.meegid.2013.03.012

Gladieux, P., Vercken, E., Fontaine, M. C., Hood, M. E., Jonot, O., Couloux, A., \& Giraud, T. (2011). Maintenance of fungal pathogen species that are specialized to different hosts: allopatric divergence and introgression through secondary contact. Molecular Biology and Evolution, 28(1), 459-471. doi: 10.1093/molbev/msq235

Godé, C., Touzet, P., Martin, H., Lahiani, E., Delph, L. F., \& Arnaud, J.-F. (2014). Characterization of 24 polymorphic microsatellite markers for Silene nutans, a gynodioecious-gynomonoecious species, and cross-species amplification in other Silene species. Conservation Genetics Resources, 6(4), 915-918. doi: 10.1007/s12686-0140240-6

Hafner, M. S., Page, R. D. M. (1995). Molecular phylogenies and host-parasite cospeciation: gophers and lice as a model system. Philosophical Transactions of the Royal Society of London. Series B: Biological Sciences, 349(1327), 77-83. doi: 10.1098/rstb.1995.0093

Hartmann, F. E., Rodríguez de la Vega, R. C., Brandenburg, J.-T., Carpentier, F., \& Giraud, T. (2018). Gene presence-absence polymorphism in castrating anther-smut fungi: recent gene gains and phylogeographic structure. Genome Biology and Evolution, 10(5), 12981314. doi: 10.1093/gbe/evy089

Hartmann, F. E., Rodríguez de la Vega, R. C., Carpentier, F., Gladieux, P., Cornille, A., Hood, M. E., \& Giraud, T. (2019). Understanding adaptation, coevolution, host specialization, and mating system in castrating anther-smut fungi by combining population and comparative genomics. Annual Review of Phytopathology, 57(1), 431-457. doi: 10.1146/annurev-phyto-082718-095947

Hood, M. E., Antonovics, J., Wolf, M., Stern, Z. L., Giraud, T., \& Abbate, J. L. (2019). Sympatry and interference of divergent Microbotryum pathogen species. Ecology and Evolution, O(0). doi: 10.1002/ece3.5140 
884

885

886

887

888

889

890

891

892

893

894

895

896

897

898

899

900

901

902

903

904

905

906

907

908

909

910

911

912

913

914

915

916

917

918

919

920

921

922

923

924

925

926

927

928

929

930
Huson, D. H. (1998). SplitsTree: analyzing and visualizing evolutionary data. Bioinformatics (Oxford, England), 14(1), 68-73.

Huson, D. H., \& Bryant, D. (2006). Application of phylogenetic networks in evolutionary studies. Molecular Biology and Evolution, 23(2), 254-267. doi: 10.1093/molbev/msj030

Jakobsson, M., \& Rosenberg, N. A. (2007). CLUMPP: a cluster matching and permutation program for dealing with label switching and multimodality in analysis of population structure. Bioinformatics, 23(14), 1801-1806. doi: 10.1093/bioinformatics/btm233

Jombart, T. (2008). adegenet: a R package for the multivariate analysis of genetic markers. Bioinformatics, 24(11), 1403-1405. doi: 10.1093/bioinformatics/btn129

Jombart, T., \& Ahmed, I. (2011). adegenet 1.3-1: new tools for the analysis of genome-wide SNP data. Bioinformatics, 27(21), 3070-3071. doi: 10.1093/bioinformatics/btr521

Jürgens, A., Witt, T., \& Gottsberger, G. (1996). Reproduction and pollination in central European populations of Silene and Saponaria species. Botanica Acta, 109(4), 316-324. doi: 10.1111/j.1438-8677.1996.tb00579.x

Kaltz, O., Gandon, S., Michalakis, Y., \& Shykoff, J. A. (1999). Local maladaptation in the anther-smut fungus Microbotryum violaceum to its host plant Silene latifolia: evidence from a cross-inoculation experiment. Evolution; International Journal of Organic Evolution, 53(2), 395-407. doi: 10.1111/j.1558-5646.1999.tb03775.x

Keenan, K., McGinnity, P., Cross, T. F., Crozier, W. W., \& Prodöhl, P. A. (2016). diveRsity: An $\mathrm{R}$ package for the estimation and exploration of population genetics parameters and their associated errors. Methods in Ecology and Evolution, 782-788. doi: 10.1111/2041210X.12067@10.1111/(ISSN)2041-210X.ecologyandevolutionireland

Kemler, M., Göker, M., Oberwinkler, F., \& Begerow, D. (2006). Implications of molecular characters for the phylogeny of the Microbotryaceae (Basidiomycota: Urediniomycetes). BMC Evolutionary Biology, 6, 35. doi: 10.1186/1471-2148-6-35

Kephart, S., Reynolds, R. J., Rutter, M. T., Fenster, C. B., \& Dudash, M. R. (2006). Pollination and seed predation by moths on Silene and allied Caryophyllaceae: evaluating a model system to study the evolution of mutualisms. New Phytologist, 169(4), 667-680. doi: 10.1111/j.1469-8137.2005.01619.x

Lafuma, L., \& Maurice, S. (2006). Reproductive characters in a gynodioecious species, Silene italica (Caryophyllaceae), with attention to the gynomonoecious phenotype. Biological Journal of the Linnean Society, 87(4), 583-591. doi: 10.1111/j.1095-8312.2006.00597.x

Lahiani, E., Dufaÿ, M., Castric, V., Le Cadre, S., Charlesworth, D., Van Rossum, F., \& Touzet, P. (2013). Disentangling the effects of mating systems and mutation rates on cytoplamic diversity in gynodioecious Silene nutans and dioecious Silene otites. Heredity, 111(2), 157-164. doi: 10.1038/hdy.2013.32

Laine, A.-L. (2005). Spatial scale of local adaptation in a plant-pathogen metapopulation. Journal of Evolutionary Biology, 18(4), 930-938. doi: 10.1111/j.1420-9101.2005.00933.x

Laine, A.-L. (2008). Temperature-mediated patterns of local adaptation in a natural plantpathogen metapopulation. Ecology Letters, 11(4), 327-337. doi: 10.1111/j.14610248.2007.01146.x

Laine, A.-L., Barrès, B., Numminen, E., \& Siren, J. P. (2019). Variable opportunities for outcrossing result in hotspots of novel genetic variation in a pathogen metapopulation. ELife, 8. doi: 10.7554/eLife.47091

Langmead, B., Trapnell, C., Pop, M., \& Salzberg, S. L. (2009). Ultrafast and memory-efficient alignment of short DNA sequences to the human genome. Genome Biology, 10(3), R25. doi: $10.1186 / \mathrm{gb}-2009-10-3-\mathrm{r} 25$ 
Le Gac, M., Hood, M. E., Fournier, E., \& Giraud, T. (2007). Phylogenetic evidence of hostspecific cryptic species in the anther smut fungus. Evolution; International Journal of Organic Evolution, 61(1), 15-26. doi: 10.1111/j.1558-5646.2007.00002.x

Le Gac, M., Hood, M. E., \& Giraud, T. (2007). Evolution of reproductive isolation within a parasitic fungal species complex. Evolution, 61(7), 1781-1787. doi: 10.1111/j.15585646.2007.00144.x

Linde, C. C., Zhan, J., \& McDonald, B. A. (2002). Population structure of Mycosphaerella graminicola: from lesions to continents. Phytopathology, 92(9), 946-955. doi: 10.1094/PHYTO.2002.92.9.946

Liu, S., Cornille, A., Decroocq, S., Tricon, D., Chague, A., Eyquard, J.-P., ... Decroocq, V. (2019). From hybrid speciation of wild Armeniaca species to multiple domestication events in Eastern Asia: the complex evolutionary history of apricots. Under Review.

López-Villavicencio, M., Jonot, O., Coantic, A., Hood, M. E., Enjalbert, J., \& Giraud, T. (2007). Multiple infections by the anther smut pathogen are frequent and involve related strains. PLOS Pathogens, 3(11), e176. doi: 10.1371/journal.ppat.0030176

Lutz, M., Göker, M., Piatek, M., Kemler, M., Begerow, D., \& Oberwinkler, F. (2005). Anther smuts of Caryophyllaceae: Molecular characters indicate host-dependent species delimitation. Mycological Progress, 4(3), 225-238. doi: 10.1007/s11557-006-0126-4

Martin, M. (2011). Cutadapt removes adapter sequences from high-throughput sequencing reads. EMBnet.Journal, 17(1), 10-12. doi: 10.14806/ej.17.1.200

Martin, H., Touzet, P., Dufay, M., Godé, C., Schmitt, E., Lahiani, E., ... Rossum, F. V. (2017). Lineages of Silene nutans developed rapid, strong, asymmetric postzygotic reproductive isolation in allopatry. Evolution, 71(6), 1519-1531. doi: 10.1111/evo.13245

Martin, H., Touzet, P., Van Rossum, F., Delalande, D., \& Arnaud, J.-F. (2016). Phylogeographic pattern of range expansion provides evidence for cryptic species lineages in Silene nutans in Western Europe. Heredity, 116(3), 286-294. doi: 10.1038/hdy.2015.100

McCoy, K. D., Boulinier, T., \& Tirard, C. (2005). Comparative host-parasite population structures: disentangling prospecting and dispersal in the black-legged kittiwake Rissa tridactyla. Molecular Ecology, 14(9), 2825-2838. doi: 10.1111/j.1365294X.2005.02631.x

McDonald, B. A., \& Stukenbrock, E. H. (2016). Rapid emergence of pathogens in agroecosystems: global threats to agricultural sustainability and food security. Phil. Trans. R. Soc. B, 371(1709), 20160026. doi: 10.1098/rstb.2016.0026

McKenna, A., Hanna, M., Banks, E., Sivachenko, A., Cibulskis, K., Kernytsky, A., ... DePristo, M. A. (2010). The Genome Analysis Toolkit: a MapReduce framework for analyzing next-generation DNA sequencing data. Genome Research, 20(9), 1297-1303. doi: 10.1101/gr.107524.110

Michalakis, Y., Sheppard, A. W., Noel, V., \& Olivieri, I. (1993). Population structure of a herbivorous insect and its host plant on a microgeographic scale. Evolution, 47(5), 16111616. doi: $10.2307 / 2410172$

Naciri, Y., Pasquier, P.-E. D., Lundberg, M., Jeanmonod, D., \& Oxelman, B. (2017). A phylogenetic circumscription of Silene sect. Siphonomorpha (Caryophyllaceae) in the Mediterranean Basin. Taxon, 66(1), 91-108. doi: 10.12705/661.5

Nei, M. (1972). Genetic distance between populations. The American Naturalist, 106(949), 283292. doi: $10.1086 / 282771$

Nieberding, C. M., Durette-Desset, M.-C., Vanderpoorten, A., Casanova, J. C., Ribas, A., Deffontaine, V., ... Michaux, J. R. (2008). Geography and host biogeography matter for 
understanding the phylogeography of a parasite. Molecular Phylogenetics and Evolution, 47(2), 538-554. doi: 10.1016/j.ympev.2008.01.028

Nieberding, C. M., \& Olivieri, I. (2007). Parasites: proxies for host genealogy and ecology? Trends in Ecology \& Evolution, 22(3), 156-165. doi: 10.1016/j.tree.2006.11.012

Paradis, E., Claude, J., \& Strimmer, K. (2004). APE: Analyses of Phylogenetics and Evolution in R language. Bioinformatics, 20(2), 289-290. doi: 10.1093/bioinformatics/btg412

Petit, E., Silver, C., Cornille, A., Gladieux, P., Rosenthal, L., Bruns, E., ... Hood, M. E. (2017). Co-occurrence and hybridization of anther-smut pathogens specialized on Dianthus hosts. Molecular Ecology, 26(7), 1877-1890. doi: 10.1111/mec.14073

Piry, S., Luikart, G., \& Cornuet, J. M. (1999). BOTTLENECK: A computer program for detecting recent reductions in the effective population size using allele frequency data. 90, 502503.

Poulin, R. (2005). Parasite biodiversity. Smithsonian Institution.

Pritchard, J. K., Stephens, M., \& Donnelly, P. (2000). Inference of population structure using multilocus genotype data. Genetics, 155(2), 945-959.

Pudlo, P., Marin, J.-M., Estoup, A., Cornuet, J.-M., Gautier, M., \& Robert, C. P. (2016). Reliable ABC model choice via random forests. Bioinformatics, 32(6), 859-866. doi: 10.1093/bioinformatics/btv684

Purcell, S., Neale, B., Todd-Brown, K., Thomas, L., Ferreira, M. A. R., Bender, D., ... Sham, P. C. (2007). PLINK: A tool set for whole-genome association and population-based linkage analyses. The American Journal of Human Genetics, 81(3), 559-575. doi: $10.1086 / 519795$

Rameau, J.-C., Mansion, D., \& Dumé, G. (1989). Flore forestière française: Plaines et collines. Forêt privée française.

Rameau, J.-C., Mansion, D., \& Dumé, G. (2008). Flore forestière française: guide écologique illustré. Région méditerranéenne. Forêt privée française.

Raynal, L., Marin, J.-M., Pudlo, P., Ribatet, M., Robert, C. P., \& Estoup, A. (2019). ABC random forests for Bayesian parameter inference. Bioinformatics, 35(10), 1720-1728. doi: 10.1093/bioinformatics/bty867

Refrégier, G., Le Gac, M., Jabbour, F., Widmer, A., Shykoff, J. A., Yockteng, R., ... Giraud, T. (2008). Cophylogeny of the anther smut fungi and their caryophyllaceous hosts: prevalence of host shifts and importance of delimiting parasite species for inferring cospeciation. BMC Evolutionary Biology, 8, 100. doi: 10.1186/1471-2148-8-100

Saleh, D., Milazzo, J., Adreit, H., Fournier, E., \& Tharreau, D. (2014). South-East Asia is the center of origin, diversity and dispersion of the rice blast fungus, Magnaporthe oryzae. New Phytologist, 201(4), 1440-1456. doi: 10.1111/nph.12627

Stukenbrock, E. H., Banke, S., \& McDonald, B. A. (2006). Global migration patterns in the fungal wheat pathogen Phaeosphaeria nodorum. Molecular Ecology, 15(10), 2895-2904. doi: $10.1111 /$ j.1365-294X.2006.02986.X

Stukenbrock, E. H., \& McDonald, B. A. (2008). The origins of plant pathogens in agroecosystems. Annual Review of Phytopathology, 46(1), 75-100. doi: 10.1146/annurev.phyto.010708.154114

Szpiech, Z. A., Jakobsson, M., \& Rosenberg, N. A. (2008). ADZE: a rarefaction approach for counting alleles private to combinations of populations. Bioinformatics, 24(21), 24982504. doi: 10.1093/bioinformatics/btn478

Taylor, D. R., \& Keller, S. R. (2007). Historical range expansion determines the phylogenetic diversity introduced during contemporary species invasion. Evolution, 61(2), 334-345. 
doi: 10.1111/j.1558-5646.2007.00037.x examples of reciprocal influence between hosts and pathogens, from short-term to long term interactions: coevolution, cospeciation and pathogen speciation following host shifts. In Immunology and Immune System Disorders. Host-Pathogen Interactions: Genetics, Immunology and Physiology (Nova Science Publishers, pp. 37-77). NY: Barton AW.

Thines, M. (2019). An evolutionary framework for host shifts - jumping ships for survival. New Phytologist, 224(2), 605-617. doi: 10.1111/nph.16092

Thompson, J. N. (2005). The geographic mosaic of coevolution. University of Chicago Press.

Thrall, P., Biere, A., \& Antonovics, J. (1993). Plant life-history and disease susceptibility - the occurrence of Ustilago-Violacea on different species within the Caryophyllaceae. Journal of Ecology, 81(3), 489-498. doi: 10.2307/2261527

Tison, J., \& de Foucault, B. (2014). Flora gallica: flore de France (Biotope).

Toh, S. S., \& Perlin, M. H. (2016). Resurgence of less-studied smut fungi as models of phytopathogenesis in the omics age. Phytopathology, 106(11), 1244-1254. doi: 10.1094/PHYTO-02-16-0075-RVW

Tsai, Y.-H. E., \& Manos, P. S. (2010). Host density drives the postglacial migration of the tree parasite, Epifagus virginiana. Proceedings of the National Academy of Sciences, 107(39), 17035-17040. doi: 10.1073/pnas.1006225107

Tutin, T., Heywood, V., Burges, N., Valentine, D., Walters, S., \& Webb, D. (2001). Flora Europaea. Royaume-Uni: Cambridge University Press.

Van Rossum, F., Martin, H., Le Cadre, S., Brachi, B., Christenhusz, M. J. M., \& Touzet, P. (2018). Phylogeography of a widely distributed species reveals a cryptic assemblage of distinct genetic lineages needing separate conservation strategies. Perspectives in Plant Ecology, Evolution and Systematics, 35, 44-51. doi: 10.1016/j.ppees.2018.10.003

Vercken, E., Fontaine, M. C., Gladieux, P., Hood, M. E., Jonot, O., \& Giraud, T. (2010). Glacial refugia in pathogens: European genetic structure of anther smut pathogens on Silene latifolia and Silene dioica. PLOS Pathogens, 6(12), e1001229. doi: 10.1371/journal.ppat.1001229

Wegmann, D., Leuenberger, C., Neuenschwander, S., \& Excoffier, L. (2010). ABCtoolbox: a versatile toolkit for approximate Bayesian computations. BMC Bioinformatics, 11(1), 116. doi: 10.1186/1471-2105-11-116

Wickham, H. (2009). ggplot2: elegant graphics for data analysis. Springer Science \& Business Media.

Wilson, D. J., Falush, D., \& McVean, G. (2005). Germs, genomes and genealogies. Trends in Ecology \& Evolution, 20(1), 39-45. doi: 10.1016/j.tree.2004.10.009

Wolfe, N. D., Dunavan, C. P., \& Diamond, J. (2007). Origins of major human infectious diseases. Nature, 447(7142), 279-283. doi: 10.1038/nature05775

Zaffarano, P. L., McDonald, B. A., \& Linde, C. C. (2008). Rapid speciation following recent host shifts in the plant pathogenic fungus Rhynchosporium. Evolution, 62(6), 1418-1436. doi: 10.1111/j.1558-5646.2008.00390.x

\section{Data accessibility}


1068 The plant and fungal microsatellite and chloroplastic genotypes are available at dryad XXX (to

1069 be completed upon acceptance). We deposited the genome raw data at NCBI Sequence Read

1070 Archive (SRA) under the BioProject xxx (ID available upon acceptance).

1071

1072 Author contributions

1073 TG and FH conceived and designed the project with the help of FVR. TG, PT, FVR, JS and EF

1074 collected samples. AS, CG, PT, SLP and FH genotyped the samples. FH and AC performed the

1075 analyses. FH, TG and FVR wrote the manuscript. All authors read and approved the final version

1076 of the manuscript and declare no conflict of interest.

1077

1078

1079 Supporting information

1080 Additional Supporting Information may be found in the online version of this article.

1081

1082 


\section{Tables}

1084 Table 1: Comparisons of scenarios and group of scenarios used for approximate Bayesian 1085 computation (ABC) to reconstruct the fungi divergence history. Scenarios are described in 1086 Table S5 and Fig S5. Results of ABC random forest procedure are shown, with the percentage of 1087 vote for each scenario/group of scenarios, the posterior probability and the prior error rate. 


\begin{tabular}{|c|c|c|c|c|c|c|c|}
\hline$A B C$ round & Tested hypothesis & \begin{tabular}{c|}
$\begin{array}{c}\text { Number of tested } \\
\text { scenarios/group of } \\
\text { scenarios }\end{array}$ \\
\end{tabular} & Description of tested scenarios/group of scenarios & \begin{tabular}{|c|} 
Best \\
scenario/group \\
of scenarios \\
\end{tabular} & $\begin{array}{c}\text { Percentage of } \\
\text { vote }\end{array}$ & $\begin{array}{l}\text { Posterior } \\
\text { probability }\end{array}$ & $\begin{array}{c}\text { Prior error } \\
\text { rate in \% }\end{array}$ \\
\hline \begin{tabular}{c|} 
Round 1: \\
"time of divergence"
\end{tabular} & divergence time $\mathrm{T} 1, \mathrm{~T} 2, \mathrm{~T} 3$ or $\mathrm{T} 4$ & 4 groups of 3 scenarios & $\begin{array}{c}\text { group } 1 \text { (time T1): divergence-order-A-no-GF-T1, divergence-order-B-no-Gi- } \\
\text { T1, divergence-order-C-no-GF-T1 } \\
\text { group } 2 \text { (time T2): divergence-order-A-no-GF-T2, divergence-order-B-no-GF- } \\
\text { T2, divergence-order--no-G-T2 } \\
\text { group } 3 \text { (time T3): divergence-order-A-no-GF-T3, divergence-order-B-no-GF- } \\
\text { T3, divergence-order-C-no-GF-T3 } \\
\text { group } 4 \text { (time T4): divergence-order-A-no-GF-T4, divergence-order-B-no-GF- } \\
\text { T4, divergence-order-C-no-GF-T4 }\end{array}$ & $\mathrm{x}$ & $\begin{array}{l}1 \\
5 \\
43 \\
51\end{array}$ & $\begin{array}{c}0.54(+- \\
0.02)\end{array}$ & $34 \%$ \\
\hline \begin{tabular}{c|} 
Round 2: \\
"divergence order"
\end{tabular} & Order of divergence $\mathrm{A}, \mathrm{B}$ or $\mathrm{C}$ & 3 scenarios & $\begin{array}{l}\text { scenario } 1 \text { (order A): divergence-order-A-no-GF-T4 } \\
\text { scenario } 2 \text { (order B): divergence-order-B-no-GF-T4 } \\
\text { scenario } 3 \text { (order C): divergence-order-C-no-GF-T4 }\end{array}$ & $x$ & $\begin{array}{c}80 \\
5 \\
15\end{array}$ & $\begin{array}{l}0.79(+- \\
0.02)\end{array}$ & $2 \%$ \\
\hline \multirow{5}{*}{$\begin{array}{l}\text { Round 3: } \\
\text { "occurence of gene } \\
\text { flow" }\end{array}$} & $\begin{array}{l}\text { step1: } \\
\text { absence of gene flow, or gene flow } \\
\text { between nutans clusters only or } \\
\text { gene flow with the outgroup }\end{array}$ & \begin{tabular}{|c|}
3 groups of 1,6 and 6 \\
scenarios
\end{tabular} & $\begin{array}{c}\text { group } 1 \text { (no gene flow): divergence-order-A-no-GF-T4 } \\
\text { group } 2 \text { (gene flow between nutans clusters only): divergence-order-A-T4- } \\
\text { GF1, divergence-order-A-T4-GF3, divergence-order-A-T4-GF5, divergence-order-A-T4- } \\
\text { GF6, divergence-order-A-T4-GF10, divergence-order-A-T4-GF12 } \\
\text { group } 3 \text { (gene flow with the outgroup): divergence-order-A-T4-GF2, divergence- } \\
\text { order-A-T4-GF4, divergence-order-A-T4-GF7, divergence-order-A-T4-GF8, divergence- } \\
\text { order-A-T4-GF9, divergence-order-A-T4-GF11 }\end{array}$ & $\mathrm{x}$ & $\begin{array}{l}33 \\
42 \\
24\end{array}$ & $\begin{array}{c}0.60(+- \\
0.02)\end{array}$ & $5 \%$ \\
\hline & $\begin{array}{l}\text { step2: } \\
\text { continuous gene flow, secondary } \\
\text { contact or ancient migration }\end{array}$ & \begin{tabular}{|c|}
3 groups of 3,2 and 4 \\
scenarios
\end{tabular} & $\begin{array}{c}\text { group } 1 \text { (continuous gene flow): divergence-order-A-T4-GF1, divergence-order-A-T4- } \\
\text { GF5, divergence-order-A-T4-GF6 } \\
\text { group } 2 \text { (secondary contact): divergence-order-A-T4-GF3, divergence-order-A-T4- } \\
\text { GF3b } \\
\text { group } 3 \text { (ancient migration): divergence-order-A-T4-GF10, divergence-order-A-T4- } \\
\text { GF10b, divergence-order-A-T4-GF12, divergence-order-A-T4-GF12b }\end{array}$ & $\mathrm{x}$ & $\begin{array}{l}23 \\
3 \\
74\end{array}$ & $\begin{array}{c}0.76(+- \\
0.02)\end{array}$ & $35 \%$ \\
\hline & $\begin{array}{l}\text { step3: } \\
\text { absence of gene flow vs ancient } \\
\text { migration }\end{array}$ & $\begin{array}{l}2 \text { groups of } 1 \text { and } 4 \\
\text { scenarios }\end{array}$ & $\begin{array}{l}\text { group } 1 \text { (no gene flow): divergence-order-A-no-GF-T4 } \\
\text { group } 2 \text { (ancient migration): divergence-order-A-A4-GF10, divergence-order-A-T4- } \\
\text { GF10b, divergence-order-A-T4-GF12, divergence-order-A-T4-GF12b }\end{array}$ & $\mathrm{x}$ & $\begin{array}{l}34 \\
66\end{array}$ & $\begin{array}{c}0.66(+- \\
0.02)\end{array}$ & $2.50 \%$ \\
\hline & $\begin{array}{c}\text { step4: } \\
\text { absence of gene flow vs secondary } \\
\text { contact }\end{array}$ & $\begin{array}{l}2 \text { groups of } 1 \text { and } 3 \\
\text { scenarios }\end{array}$ & $\begin{array}{c}\text { group } 1 \text { (no gene flow): divergence-order-A-no-GF-T4 } \\
\text { group } 2 \text { (secondary contact): divergence-order-A-T4-GF3, divergence-order-A-T4- } \\
\text { GF3b }\end{array}$ & $\mathrm{x}$ & $\begin{array}{c}99 \\
1\end{array}$ & $\begin{array}{l}0.99(+- \\
0.004)\end{array}$ & $0.76 \%$ \\
\hline & $\begin{array}{c}\text { Step5: } \\
\begin{array}{c}\text { comparison of different scenarios of } \\
\text { ancient migration }\end{array}\end{array}$ & 4 scenarios & $\begin{array}{l}\text { scenario 1: divergence-order-A-T4-GF10 } \\
\text { scenario 2: divergence-order-A-T4-GF10b } \\
\text { scenario 3: divergence-order-A-T4-GF12 } \\
\text { scenario 4: divergence-order-A-T4-GF12b }\end{array}$ & $x$ & $\begin{array}{l}29 \\
24 \\
26 \\
21\end{array}$ & $\begin{array}{c}0.49(+- \\
0.03)\end{array}$ & $60 \%$ \\
\hline
\end{tabular}


1090 Figures

1091 Figure 1: Population genetic structure of Silene nutans and $S$. italica host plants based on six plastid (chloroplast) SNPs and 21 microsatellite markers. A. Plastid haplotypes according to their geographic distribution. On the right, a zoom of the map in the northeastern region of France and Belgium is shown. The size of the symbols is proportional to the number of individuals sampled by site (1-9 plants). B. Principal component analysis (PCA), with information of plastid haplotypes. The first and second principal component axes are shown and the percentage of variance explained by each axis is indicated into brackets. C. Results of STRUCTURE on both host plant species for $\mathrm{K}=5$ clusters. On panels $\mathrm{A}$ and $\mathrm{B}$, symbol shape indicates species and color indicates plastid haplotypes. The two genetic clusters identified within the orange plastid haplotype based on the STRUCTURE analysis (panel C) are shown with light and dark orange colors, respectively.

Figure 2: Population genetic structure of anther-smut fungi (Microbotryum) parasitizing Silene nutans and $S$. italica based on 22 microsatellite markers. A. Anther-smut fungi parasitizing S. italica (top; photo credit M.E. Hood) and S. nutans (bottom; photo credit M. Strack van Schijndel). B. Principal component analysis (PCA). The first and second principal component axes are shown and the percentage of variance explained by each axis is indicated into brackets. The symbol shape indicates the sampling host species. The dark and light blue colors indicate assignment probability $>0.80$ to the two corresponding clusters identified in the STRUCTURE analysis for $\mathrm{K}=2$ (see panel C). Pink color indicates strains for which no cluster could be assigned with a probability $>0.80$. Genetic variance explained by the principal component axes is shown in the right bottom corner. C. STRUCTURE barplot for $\mathrm{K}=2$. Strains are ordered according to their sampling host species.

Figure 3: Congruence of population genetic structure between Silene nutans host plants and their anther-smut fungal (Microbotryum) strains based on microsatellite markers. A. Principal component analysis (PCA) on the fungal strains with information of the population genetic structure of their hosts. The first and second principal component axes are shown. Symbol shape indicates the sampling host species and color indicates the plastid haplotypes of the sampling host. B. STRUCTURE barplots for (1) K=3 in 112 Microbotryum strains and (2) $\mathrm{K}=4$ in $110 \mathrm{~S}$. nutans plant individuals. Fungal strains are ordered according to their sampling host plastid haplotypes. Host plant individuals are ordered according to their plastid haplotypes. C. Map of mean cluster membership proportions per site for (1) the 112 fungal strains in the STRUCTURE analysis at $\mathrm{K}=3$ and (2) the $110 \mathrm{~S}$. nutans plant individuals in the STRUCTURE analysis at $\mathrm{K}=4$. The pie diameter reflects the sample size in the corresponding site (1 - 14 individuals). 
1131 Figure 5: Absence of genome-wide signature of recent gene flow among anther-smut fungal 1132 strains parasitizing closely related Silene species. A. Principal component analysis (PCA) 1133 based on 1,305,369 genome-wide SNPs. B. STRUCTURE analyses based on 233 unlinked SNPs 1134 for $\mathrm{K}=5$. The $\mathrm{Y}$ axis indicates the estimated membership proportions in the $K$ clusters for each 1135 fungal strain (X axis). C. Neighbornet tree from a SplitsTree analysis based on 595,002 genome1136 wide SNPs with no missing data and heterozygote genotypes. The inner plot shows a zoom of the 1137 tip of the tree for strains parasitizing S. nutans. Information on the species or plastid haplotype of 1138 the host of sampling of the strains is given. 
A

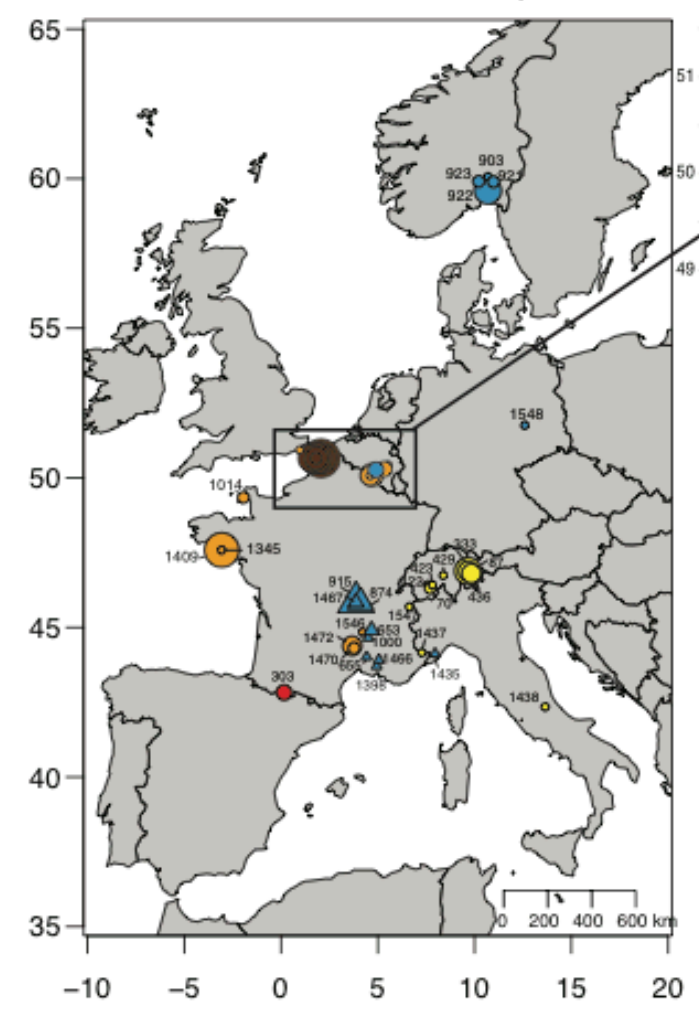

B
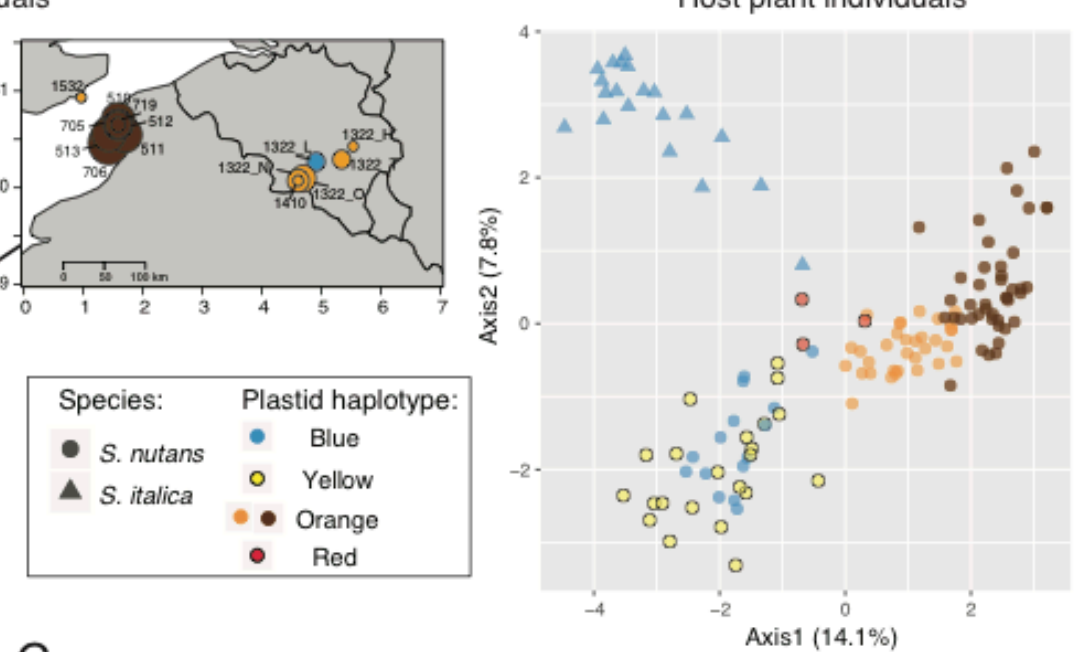

C

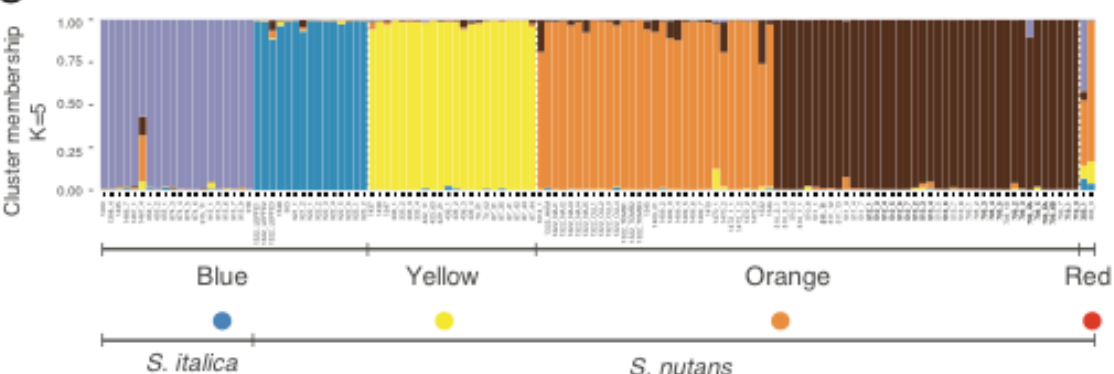

S. nutans

Host plant individuals, plastid haplotypes and species

Figure 1 

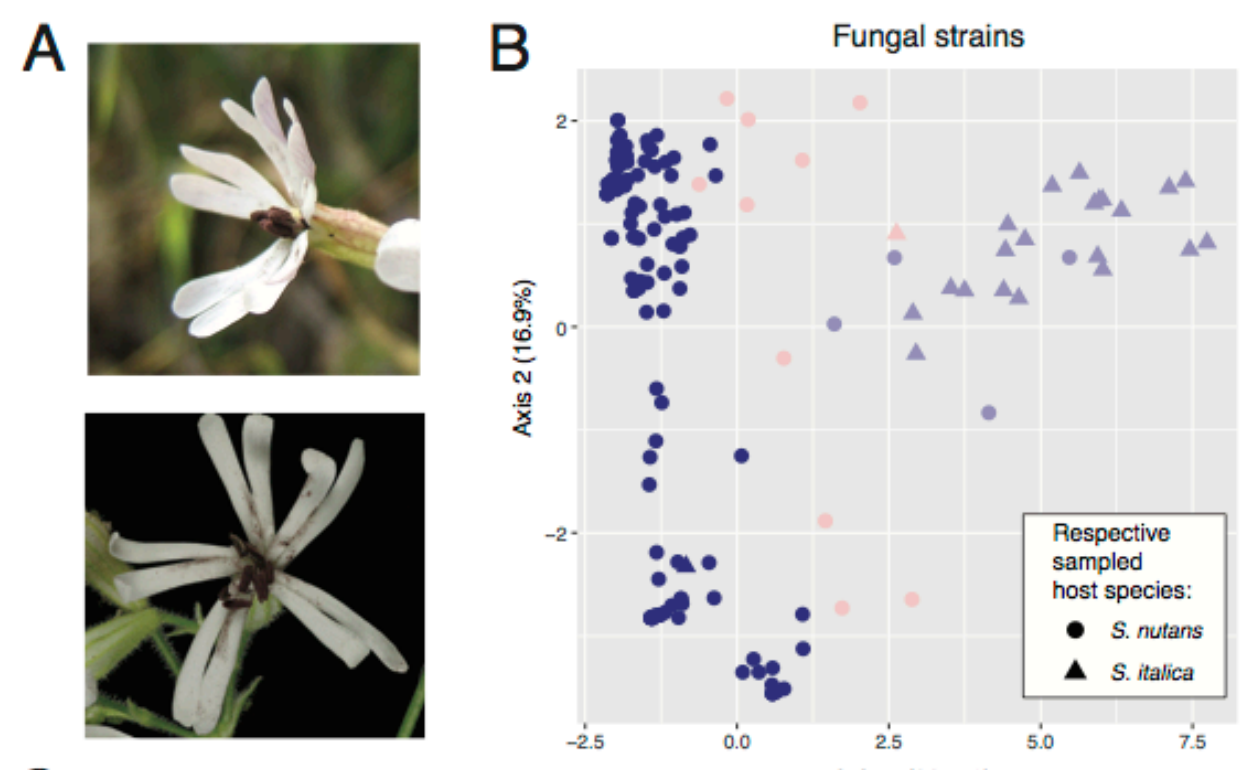

C

Axis $1(33.1 \%)$

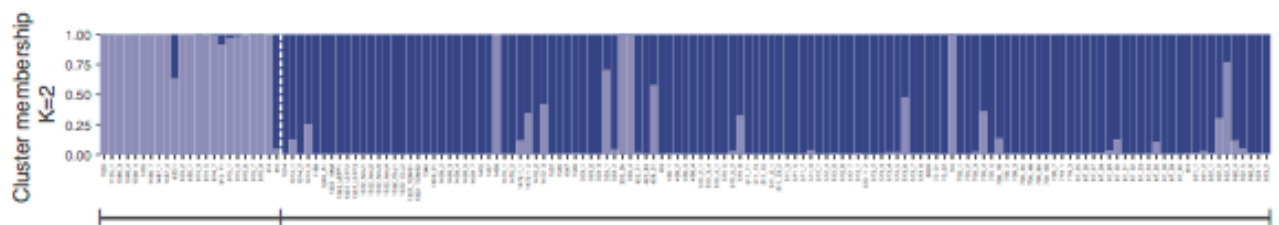

S. italica

S. nutans

Fungal strains and their respective sampled host species

Figure 2 
bioRxiv preprint doi: https://doi.org/10.1101/2020.01.04.894774; this version posted January 6, 2020. The copyright holder for this preprint (which was not certified by peer review) is the author/funder. All rights reserved. No reuse allowed without permission.
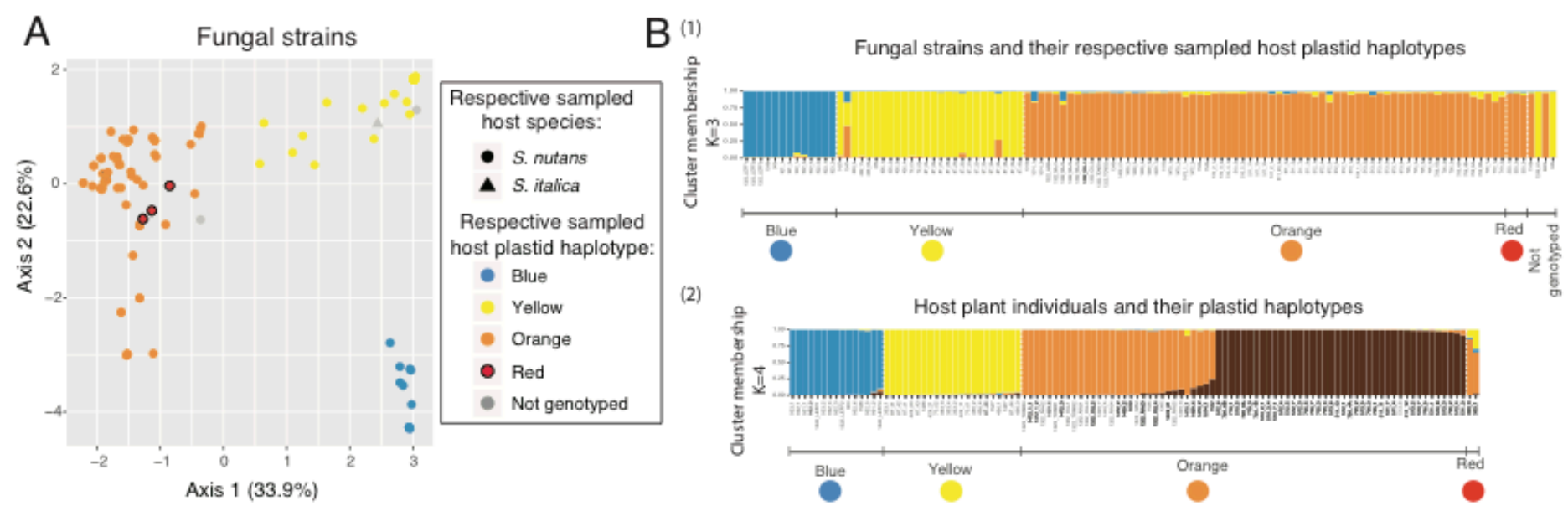

C

Fungal strains
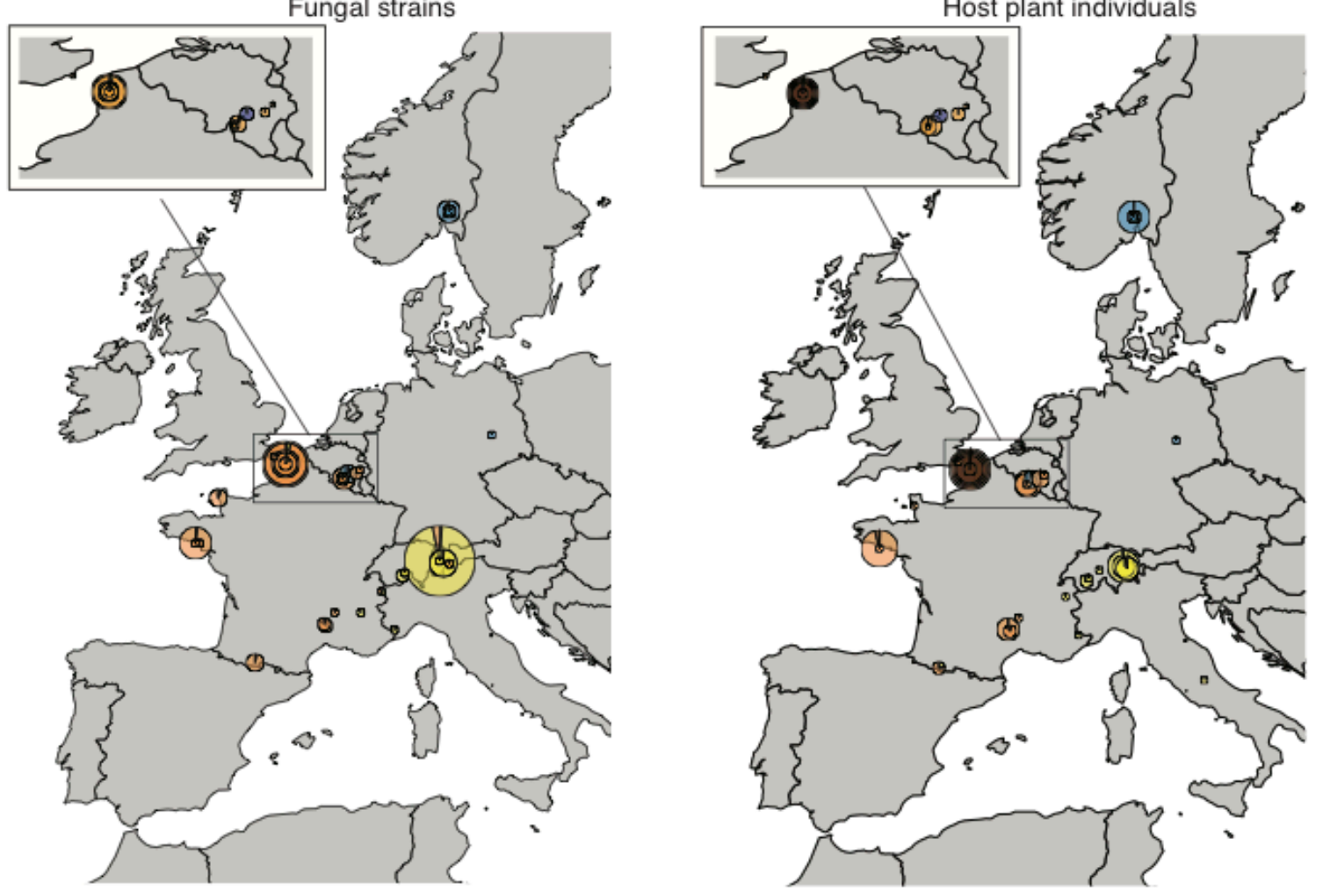

Figure 3 
bioRxiv preprint doi: https://doi.org/10.1101/2020.01.04.894774; this version posted January 6, 2020. The copyright holder for this preprint (which was not certified by peer review) is the author/funder. All rights reserved. No reuse allowed without permission.

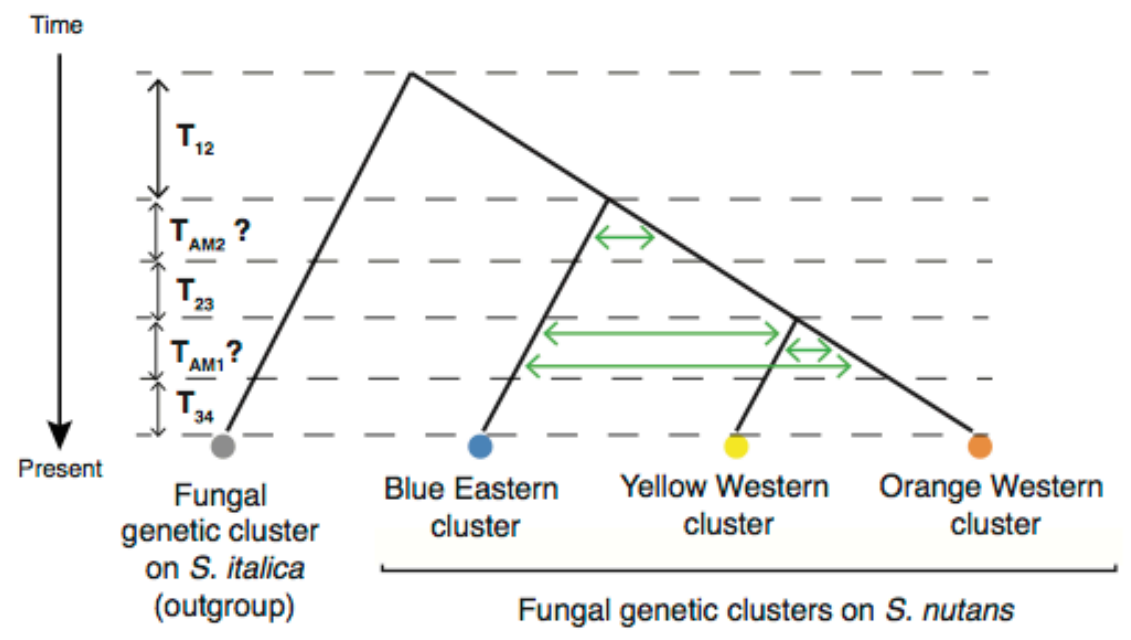

Figure 4 
bioRxiv preprint doi: https://doi.org/10.1101/2020.01.04.894774; this version posted January 6, 2020. The copyright holder for this preprint (which was not certified by peer review) is the author/funder. All rights reserved. No reuse allowed without permission.

A
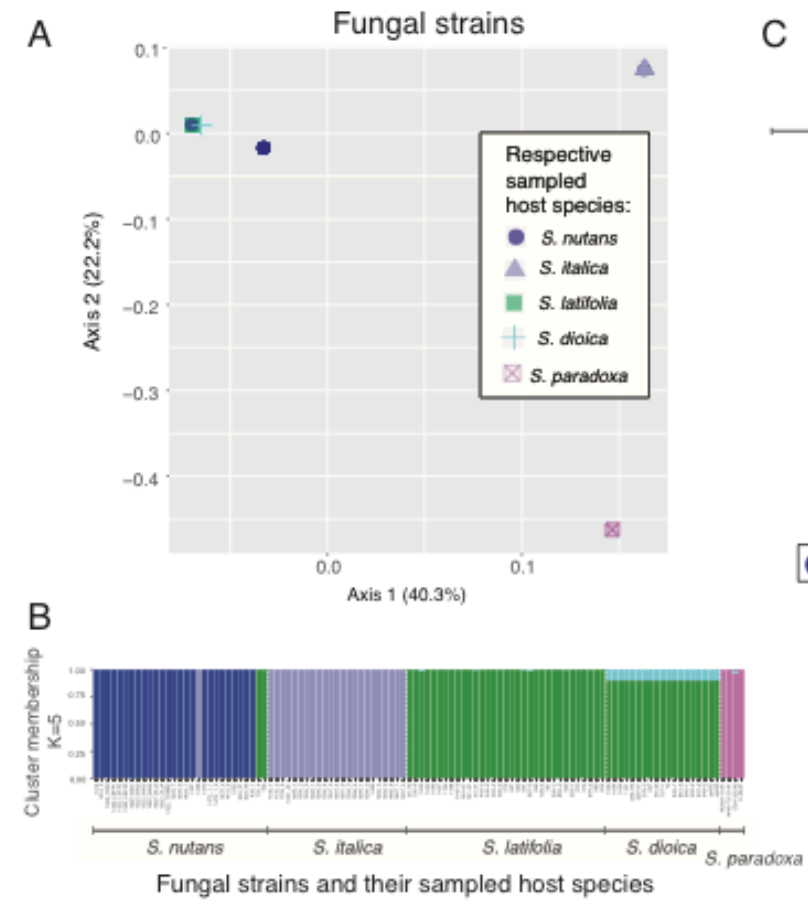

C

Fungal strains

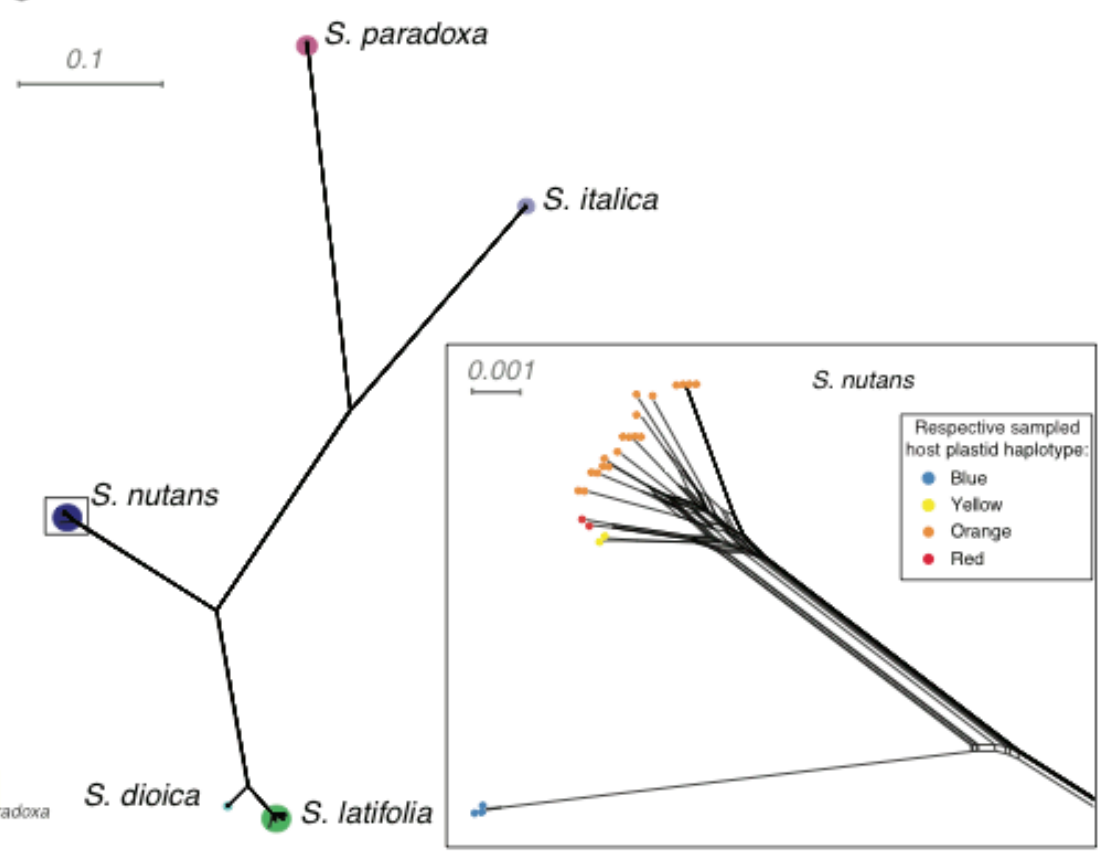

Figure 5 